\title{
Neonatal Hyperoxia Exposure Disrupts Axon- Oligodendrocyte Integrity in the Subcortical White Matter
}

\author{
Jonathan Ritter, ${ }^{1,2}$ Thomas Schmitz, ${ }^{3}$ Li-Jin Chew, ${ }^{1}$ Christoph Bührer, ${ }^{3}$ Wiebke Möbius, ${ }^{4}$ Marzieh Zonouzi, ${ }^{1}$ \\ and Vittorio Gallo ${ }^{1}$ \\ ${ }^{1}$ Center for Neuroscience Research, Children's National Medical Center, Washington, District of Columbia 20010, ${ }^{2}$ Department of Pharmacology and \\ Physiology, Georgetown University, Washington, District of Columbia 20057, ${ }^{3}$ Charité Universitätsmedizin, Clinic for Neonatalogy, 13353 Berlin, Germany, \\ and ${ }^{4}$ Max-Planck-Institute of Experimental Medicine, Department of Neurogenetics, 37075 Göttingen, Germany
}

The pathological mechanisms underlying neurological deficits observed in individuals born prematurely are not completely understood. A common form of injury in the preterm population is periventricular white matter injury (PWMI), a pathology associated with impaired brain development. To mitigate or eliminate PWMI, there is an urgent need to understand the pathological mechanism(s) involved on a neurobiological, structural, and functional level. Recent clinical data suggest that a percentage of premature infants experience relative hyperoxia. Using a hyperoxic model of premature brain injury, we have previously demonstrated that neonatal hyperoxia exposure in the mouse disrupts development of the white matter (WM) by delaying the maturation of the oligodendroglial lineage. In the present study, we address the question of how hyperoxia-induced alterations in WM development affect overall WM integrity and axonal function. We show that neonatal hyperoxia causes ultrastructural changes, including: myelination abnormalities (i.e., reduced myelin thickness and abnormal extramyelin loops) and axonopathy (i.e., altered neurofilament phosphorylation, paranodal defects, and changes in node of Ranvier number and structure). This disruption of axon- oligodendrocyte integrity results in the lasting impairment of conduction properties in the adult WM. Understanding the pathology of premature PWMI injury will allow for the development of interventional strategies to preserve WM integrity and function.

\section{Introduction}

Preterm birth has become a significant pediatric public health concern (Mathews et al., 2011), with many survivors exhibiting cognitive, behavioral, and attention deficits in adolescence and adulthood (Ment et al., 2003; Litt et al., 2005; Allin et al., 2006; Volpe, 2008; Volpe, 2009; Allin et al., 2011). Periventricular white matter injury (PWMI) is thought to be the principal cause of motor and/or cognitive deficits observed in surviving preterm infants. Diffusion tensor MRI studies have detected microstructural abnormalities throughout the developing and adult white matter (WM) in individuals born prematurely (Allin et al., 2011; Skiöld et al., 2012; Thompson et al., 2011; Iwata et al., 2012).

The preterm period in humans, and early postnatal development in rodents, is a time of active oligodendrogenesis, myelination, and axonal organization in the developing subcortical WM

\footnotetext{
Received Nov. 30, 2012; revised April 3, 2013; accepted April 14, 2013.

Author contributions: J.R., T.S., L.-J.C., C.B., M.Z., and V.G. designed research; J.R., T.S., and W.M. performed research; J.R., T.S., L.-J.C., C.B., and W.M. analyzed data; J.R., T.S., L.-J.C., and V.G. wrote the paper.

This work was supported by National Institutes of Health (Grant \#R01 NS056427, Grant \#R21 NS078731, Grant \#T32 HD046388, Grant \#P01 NS062686, and \#R01 NS045702 to V.G.), the Intellectual and Developmental Disabilities Research Center (Grant \#P30 HD40677), and the Sanitaetsrat Dr. Emil Alexander Huebner and Gemahlin Foundation, Germany (to T.S.). T. S. was also supported by Grant SCHM 3007/2-1 from the Deutsche Forschungsgemeinschaft (DFG). L.-J.C. was supported by National Multiple Sclerosis Society Grant 3954A1/2. We thank Drs. Regina Armstrong, Karen Gale, Ken Kellar, Judy Liu, and Barry Wolfe for discussions and the critical reading of portions of this manuscript.

The authors declare no competing financial interests.

Correspondence should be addressed to Vittorio Gallo, PhD, Center for Neuroscience Research, Children's National Medical Center, 111 Michigan Avenue, NW, Washington, DC 20010-2970. E-mail:vgallo@cnmcresearch.org.

DOI:10.1523/JNEUROSCI.5528-12.2013

Copyright $\odot 2013$ the authors $\quad 0270-6474 / 13 / 338990-13 \$ 15.00 / 0$
}

(Baumann and Pham-Dinh, 2001; Craig et al., 2003; Poliak and Peles, 2003; Bradl and Lassmann, 2010). It is a stage of development when the WM displays enhanced vulnerability to such insults as hypoxia-ischemia, chronic hypoxia, inflammation, and excitotoxicity (Back, 2006; Khwaja and Volpe, 2008; Scafidi et al., 2009; Volpe, 2009). Recent evidence indicates an additional, poorly understood threat of hyperoxia, which may potentially arise from premature delivery (Sorensen and Greisen, 2009) and/or placental dysfunction (Lee et al., 2013), suggesting an association of blood gas abnormalities with neurodevelopmental disability (Leviton et al., 2010). This has prompted investigation into the specific effects of high normobaric oxygen using rodent models.

Hyperoxia in the neonatal rodent causes a maturationdependent increase in cell apoptosis throughout the developing WM (Felderhoff-Mueser et al., 2004; Gerstner et al., 2008) followed by a delay in WM maturation (Gerstner et al., 2008; Schmitz et al., 2011). Demonstrated mechanisms of injury include astrocyte dysfunction, altered glutamate homeostasis (Schmitz et al., 2011), and oxidative stress (Gerstner et al., 2008). The hyperoxia-induced delay in WM maturation results in a persistent decrease in fractional anisotropy (Schmitz et al., 2011) and leads to hyperactivity and motor coordination deficits in adulthood (Schmitz et al., 2012). These analyses raise important questions about how disturbing development affects WM structural and functional integrity.

In the present study, we determined the effects of neonatal hyperoxia on the ultrastructural and functional integrity of the subcortical WM. We discovered that hyperoxia exposure dis- 
rupted developmental myelination and caused a decrease in the diameter of myelinated axons until postnatal day 30 (P30). These changes were associated with reduced expression of several major myelin proteins, abnormal myelin structures, and changes in neurofilament (NF) phosphorylation. Hyperoxia exposure was also found to further disrupt axon-oligodendrocyte integrity by altering the formation of the paranodal segment and disturb the proper organization of the nodes of Ranvier on myelinated axons. Finally, these structural abnormalities resulted in decreased conduction amplitude and velocity of axons in the adult corpus callosum (CC). Therefore, neonatal hyperoxia exposure disrupts WM maturation during a critical window of development, causing lasting ultrastructural and functional changes in myelin and underlying axons. These findings provide important insight into the pathogenesis of long-term, hyperoxia-induced WM damage.

\section{Materials and Methods}

Neonatal hyperoxia paradigm. This protocol was described previously (Schmitz et al., 2011). Briefly, male and female, 6-d-old (P6) C57B/L6 wild-type mice were divided into hyperoxia and control groups and subjected to hyperoxia by being placed, along with their mothers, in a chamber containing $80 \% \mathrm{O}_{2}$ for $48 \mathrm{~h}$. All control pups for each litter were kept in room air with a second lactating mother. After hyperoxia exposure, all pups were reunited with their biological mother and kept in room air until being killed. The overall health of the pups exposed to hyperoxia was normal. Analysis of blood oxygenation, metabolic status, and weight were described previously (Schmitz et al., 2011). All values compared between the control and hyperoxia group were not significantly different except for $\mathrm{pO}_{2}$ levels, for which mice exposed to neonatal hyperoxia exhibited a 2.3 -fold increase.

Immunofluorescence. Mice were anesthetized, transcardially perfused with PBS and $4 \% \mathrm{PFA}$, and postfixed in $4 \%$ PFA overnight at $4^{\circ} \mathrm{C}$ for all developmental time points (P12, P15, P30, and P60). Fixed brains were then placed in $20 \%$ glycerol in PBS for $24 \mathrm{~h}$ and stored in $10 \%$ glycerol in PBS. Tissue sections for immunofluorescence were obtained by mounting brains with freezing medium (Triangle Biomedical Sciences) on a microtome (HM400; Microm International). Sections were cut at 30-40 $\mu \mathrm{m}$ and stored in a $0.05 \%$ sodium azide/PBS solution. Immunohistochemistry was performed by first placing slices in blocking solution containing $1 \%$ BSA, $0.3 \%$ Triton X-100, and 20\% NGS in $1 \times$ PBS for at least $1 \mathrm{~h}$ at room temperature. Primary antibodies were diluted using carrier solution containing $1 \%$ BSA, $0.3 \%$ Triton $\mathrm{X}-100$, and $1 \%$ NGS in $1 \times$ PBS.

Sections used for immunohistochemistry were incubated in primary antibodies at $4^{\circ} \mathrm{C}$ overnight. Three rinses in carrier solution were then performed at room temperature every $10 \mathrm{~min}$. Monoclonal mouse CC1 antibody was diluted 1:500 (EMD; Millipore). Polyclonal rabbit myelin associated glycoprotein (MAG; Santa Cruz Biotechnology) antibody was diluted 1:250. Polyclonal rabbit NF200 (Abcam) antibody was diluted 1:250. Monoclonal mouse SMI-31 and SMI-32 (Covance) antibodies were diluted 1:250. Mouse monoclonal $\beta$-amyloid (Abcam) antibody was diluted to 1:250. Rabbit polyclonal contactin associated protein (Caspr; Abcam) antibody was diluted 1:200. Rabbit polyclonal Nav1.6 (EMDl Millipore) antibody was diluted to 1:250. Sections were then put in carrier solution containing necessary secondary antibodies for $1 \mathrm{~h}$ at room temperature. All of the following secondary antibodies used were from Jackson Immunoresearch Laboratories: FITC-conjugated goat anti-mouse IgG (1:200), FITC-conjugated goat anti-rabbit IgG (1:200), CY5-conjugated goat anti-mouse IgG (1:500), CY5-conjugated goat anti-rabbit IgG (1:500), CY3/rhodamine-conjugated goat anti-mouse IgG (1:200), and CY3/rhodamine-conjugated goat anti-rabbit IgG (1: 200). Sections were then washed three times with PBS, stained with DAPI for $10 \mathrm{~min}$, and mounted on slides with Mowiol.

Western blotting. Analysis was conducted on microdissected WM tissue, which included the CC, cingulum, and external capsule. The samples were homogenized in $4^{\circ} \mathrm{C}$ RIPA buffer solution for protein extraction. After lysis, samples were centrifuged at $4^{\circ} \mathrm{C}$ for $30 \mathrm{~min}$ and aliquots were then assayed for protein concentration using a BCA kit (Pierce). Equal amounts of protein $(30 \mu \mathrm{g})$ were loaded for each sample on $4-20 \%$ mini precast Tris-glycine gels. After electrophoresis, the gels were transferred onto PVDF membranes and kept overnight at $4^{\circ} \mathrm{C}$. Immunoblotting was performed by first pageing membranes in $4 \%$ nonfat dry milk in TBST. Primary antibody concentrations were as follows: monoclonal mouse $\beta$-actin 1:1250 (EMD; Millipore), monoclonal mouse myelin basic protein (MBP) 1:1000 (Covance), polyclonal rabbit proteolipid protein (PLP) 1:500 (Abcam), myelin oligodendrocyte glycoprotein (MOG) 1:1000 (Abcam), MAG (1:500, Santa Cruz Biotechnology), and monoclonal mouse 2,3-cyclic nucleotide 3'-phosphodiesterase (CNPase) 1:1000 (Covance).

Monoclonal mouse NF200 (Abcam) antibody was diluted 1:500. Monoclonal mouse SMI-31 and SMI-32 (Covance) antibodies were diluted 1:250. HRP-conjugated secondary antibodies (anti-rabbit and anti-mouse, BD Biosciences PharMingen; anti-goat, Santa Cruz Biotechnology; anti-guinea pig, EMD Millipore) were diluted 1:2000 in 4\% milk in TBST. Chemiluminescent detection was performed using ECL SuperSignal kits (Pierce) according to the manufacturers' directions. Western blot analysis was performed by using a pairwise comparison between control and hyperoxia groups for all time points. For all samples, the optical density for each protein of interest was determined and expressed as a ratio of an internal control ( $\beta$-actin).

Real-time quantitative PCR. Subcortical WM tissue was microdissected as described above and real-time quantitative PCR (qPCR) performed as described previously with modifications (Chew et al., 2011). Briefly, total RNA was isolated using the RNAeasy Minelute cleanup kit (Qiagen) and cDNA was synthesized from 600 ng of RNA in a total volume of $20 \mu \mathrm{l}$ using the iScript cDNA Synthesis Kit (Bio-Rad). Five microliters of 1:30 diluted stock of each first-strand cDNA reaction was used for qPCR in $25 \mu \mathrm{l}$ reactions, with each reaction performed in triplicate. Real-time qPCR was performed in a spectrofluorometric thermal cycler (PRISM 7900 Sequence detector system; Applied Biosystems) using $2 \times$ Perfecta SYBR Green SuperMix with ROX (Quanta Biosciences). The three-step cycling parameters were as follows: $95^{\circ} \mathrm{C}$ for $10 \mathrm{~min}$, followed by 40 cycles of $95^{\circ} \mathrm{C}$ for $45 \mathrm{~s}, 55^{\circ} \mathrm{C}$ for $45 \mathrm{~s}$, and $72^{\circ} \mathrm{C}$ for $45 \mathrm{~s}$. Primer quality was assessed with an additional final dissociation curve of $95^{\circ} \mathrm{C}$ for $15 \mathrm{~s}, 60^{\circ} \mathrm{C}$ for $15 \mathrm{~s}$, and $95^{\circ} \mathrm{C}$ for $15 \mathrm{~s}$. The fold change in expression over controls in room air was calculated with the $\Delta \Delta \mathrm{Ct}$ method using $\beta$-actin as an internal normalization control. The primers used for PCR were as follows: mouse MOG (QuantiTect Primer assays, Qiagen), MBP forward, 5'-ATGGCATCACAGAAGAGACCCTCA-3'; MBP reverse, 5'-TAAAGAAGCGCCCGATGGAGTCAA-3'; PLP forward, 5' -AGCGGGTGTGTCATTGTTTGGGAA-3'; PLP reverse, 5' -AC CATACATTCTGGCATCAGCGCA-3'; MAG forward $5^{\prime}$-TGCCATTG TCTGCTACATCACCCCA-3'; MAG reverse 5' -ACTTATCAGGTGCT CCAGAGATTCGG-3' ${ }^{\prime}$, CNPase forward $5^{\prime}$-TACTTCGGCTGGTTCC TGAC-3'; CNPase reverse 5' -GCCTTCCCGTAGTCACAAAA- ${ }^{\prime}$; actin forward 5'-GAAGAGCTATGAGCTGCCTGAC-3'; actin reverse 5' -AG GTCTTTACGGATGTCAACGT-3'.

Confocal microscopy and quantitative analysis. Analysis of immunofluorescence after immunohistochemistry was done using a Zeiss confocal laser scanning microscopic. Optical sections were acquired using ZEN software under a $40 \times, 63 \times$, or $100 \times$ objective. Field depth ranged from 10 to $15 \mu \mathrm{m}$ and four different laser lines were used for imaging: FITC (488 nm excitation, 522/35 emission filter), CY3 (560 nm excitation, 605/32 emission filter), Cy5 (647 nm excitation, 680/32 emission filter), and DAPI (400 nm excitation). Images were collapsed and quantification was determined in the $x, y$, and $z$ planes. An average of three images were taken from the CC, cingulum, and external capsule regions within two to three sections for each animal analyzed. Image Examiner 4.02 and ImageJ software were used to merge images for analysis.

Compound action potentials. C57B/L6 wild-type mice exposed to hyperoxia, along with their litter-matched control counterparts, were anesthetized with isoflurane at $\mathrm{P} 30$ and $\mathrm{P} 60$ for compound action potential (CAP) analysis. Once removed, brains were rapidly placed in ice-cold slicing solution containing the following (in $\mathrm{mm}$ ): $85 \mathrm{NaCl}, 2.5 \mathrm{KCl}, 25$ $\mathrm{NaHCO}_{3}, 1.25 \mathrm{NaH}_{2} \mathrm{PO}_{4}, 0.5 \mathrm{CaCl}_{2}, 7 \mathrm{MgCl}_{2}, 25$ glucose, and 75 sucrose, $\mathrm{pH} 7.4$, bubbled in $95 \% \mathrm{O}_{2} / 5 \% \mathrm{CO}_{2}$. Coronal slices $400 \mu \mathrm{m}$ in thickness 
were obtained using a VT1000S Vibratome (Leica) and placed for $30 \mathrm{~min}$ in an incubating chamber containing recording solution containing the following (in mM): $125 \mathrm{NaCl}, 2.5 \mathrm{KCl}, 26 \mathrm{NaHCO}_{3}, 1.25 \mathrm{NaH}_{2} \mathrm{PO}_{4}, 2.5$ $\mathrm{CaCl}_{2}, 1.3 \mathrm{MgCl}_{2}$, and 11 glucose, $\mathrm{pH} 7.4$, bubbled in $95 \% \mathrm{O}_{2} / 5 \% \mathrm{CO}_{2}$ and maintained at $37^{\circ} \mathrm{C}$. Slices were then kept in the same recording solution at room temperature $\left(22-25^{\circ} \mathrm{C}\right)$ for $3-4 \mathrm{~h}$ until time for electrophysiological analysis. Three slices for each animal at both P30 and P60 were analyzed for CAP recordings corresponding to sections 14-17 (bregma 0.74 to $-1.28 \mathrm{~mm}$ ) of the National Institutes of Mental Health's mouse brain atlas (http://www.mbl.org/atlas170/atlas170_frame.html). Slices were placed in a recording chamber superfused with oxygenated recording solution at a flow rate of $2 \mathrm{ml} / \mathrm{min}$ and viewed using the $10 \times$ objective of an Olympus BX61WI microscope. CAP recordings were obtained using extracellular field electrodes with a tip resistance of $1 \mathrm{M} \Omega$ and filled with recording solution connected to a Multiclamp 700B amplifier connected via a Digidata 1322A interface (Molecular Devices). A bipolar Ni-Cr stimulating electrode ( $\sim 200 \mu \mathrm{m}$ tip separation) connected to a constant current stimulator DS3 (Digitimer; 100-200 $\mu \mathrm{A}$ ) and a computer using pClamp (Clampex 10.2). The stimulating and recording electrodes were placed $\sim 2 \mathrm{~mm}$ apart $(\sim 1 \mathrm{~mm}$ on each side of the midline) in the CC of subcortical WM and a constant stimulus of 700 pA was delivered to each slice in current clamp for each recording. A paired pulse protocol was used with 2 stimulations per pulse and a duration of $0.2 \mathrm{~ms}$ between stimulations. The pulse frequencies were $200 \mathrm{~Hz}$ and had a period of $5 \mathrm{~ms}$. Ten sweeps, each an average of 10 pulses, were acquired and used in analysis for CAP amplitude and conduction velocity. Two distinguishable downward waves were evident for each CAP recording, with the first corresponding to rapidly propagating myelinated $(\mathrm{M})$ axons and the second to slower propagating unmyelinated (UM) axons. The maximum CAP amplitude for both the M and UM waves were used for analysis. To measure conduction velocity for the $\mathrm{M}$ wave, the time duration (in milliseconds) to reach maximum amplitude from baseline was determined. The conduction velocity of the UM wave was found from measuring the time duration (in milliseconds) from the baseline until the maximum amplitude of the UM wave.

Electron microscopy. Mice were transcardially perfused with a fixation buffer containing $2.5 \%$ glutaraldehyde and $4 \%$ paraformaldehyde for 20 min, followed by a perfusion with a phosphate buffer at room temperature for $3 \mathrm{~min}$. To reduce myelin damage, each perfusion was done with an automated perfusion pump with a constant flow of $15 \mathrm{ml} / \mathrm{h}$. Brains were then kept in the fixation buffer for $48 \mathrm{~h}$ at room temperature $\left(37^{\circ} \mathrm{C}\right)$. Coronal $200 \mu \mathrm{m}$ sections of subcortical WM tracts were obtained corresponding to sections $15-16$ (bregma $0.38-0.00 \mathrm{~mm}$ ) of the National Institutes of Mental Health's mouse brain atlas. Thin sections of $0.5 \mu \mathrm{m}$ were then collected, placed on grids, and stained with uranyl acetate and lead citrate. The grids were then imaged using a transmission electron microscope ("Leo 906"; Zeiss). Randomly selected axons (80-100 per section of the CC) were counted and classified. For one animal, 8001000 callosal axons were measured, with axons of $<0.3 \mu \mathrm{m}$ excluded from the analysis. Parameters for analysis included axonal diameter, myelin thickness, g-ratio, and delamination of the myelin sheath. A MannWhitney statistical test was used to compare animals exposed to hyperoxia and their litter-matched controls.

\section{Results}

\section{Neonatal hyperoxia alters myelin protein expression in the developing WM}

In humans, at the beginning of the third trimester, immature oligodendroglia predominate in the developing subcortical WM (Back et al., 2001; Kinney, 2006). As the third trimester progresses, these cells differentiate into mature oligodendrocytes, develop contacts with axons projecting through the subcortical $\mathrm{WM}$, and begin the myelination process (Jakovcevski et al., 2009). In the developing subcortical WM of the rodent, oligodendrocyte progenitor cells (OPCs), late oligodendrocyte progenitors, and immature oligodendrocytes become increasingly abundant in the first week of life (Back et al., 2007; Deng et al., 2008), and normal developmental myelination in the rodent sub- cortical WM begins at $\sim$ P7 (Craig et al., 2003; Deng et al., 2008). We previously found the P6 WM to contain $\sim 8.6 \%$ mature oligodendrocytes $\left(\mathrm{CC}^{+}{ }^{+}\right.$cells), 39.4\% immature oligodendrocytes $\left(\mathrm{O}^{+}{ }^{+} \mathrm{NG}^{+}\right.$and $\mathrm{O}^{+}{ }^{+} \mathrm{NG}^{-}$cells), and $42.5 \%$ OPCs $\left(\mathrm{O} 4{ }^{-}\right.$ $\mathrm{NG}^{+}{ }^{+}$cells) (Schmitz et al., 2011).

Mature oligodendrocytes of the CNS express a number of different myelin-associated proteins with various locations and distinct functions (Baumann and Pham-Dinh, 2001; Quarles et al., 2006). We have previously shown that MBP expression returns to control levels by P15 in animals exposed to neonatal hyperoxia from P6 to P8 (Schmitz et al., 2011). It is unknown whether other myelin proteins return to normal levels after neonatal hyperoxia exposure. To determine whether neonatal hyperoxia exposure disrupted developmental myelination, myelin protein expression in the WM was first measured using a time course analysis after the neonatal hyperoxia exposure. The myelin proteins analyzed included MAG, MOG, PLP, and CNPase. After hyperoxia exposure and $4 \mathrm{~d}$ of recovery in room air (P12), the protein expression of MAG, MOG, and PLP were significantly lower than in the control group. No difference was observed in the levels of CNPase (Fig. $1 A, B$ ). At P15, protein levels of MAG and PLP remained significantly lower in the hyperoxia group, but levels of MOG returned to control levels. Again, no change in CNPase protein expression was found between the two groups (Fig. $1 A, B$ ). When protein levels were determined at P30, the expression pattern was identical to that observed at P15: MAG and PLP were significantly decreased in the hyperoxia group compared with controls, with no change found in MOG or CNPase expression (Fig. 1A,B). At P60, all myelin protein expression returned to control levels in the hyperoxia group (Fig. $1 A, B)$. To determine whether myelin gene transcription was affected by hyperoxia, we also analyzed RNA levels at P12, P15, and P30 using qPCR (Table 1). Consistent with Figure 1 and our previous finding with MBP protein (Schmitz et al., 2011), MBP, MAG, and MOG RNA were all found to be significantly reduced at P12 and had recovered to control levels by P30. CNPase RNA was also decreased at P12, but did not show a corresponding change in protein (Fig. 1). This unexpected result with CNPase RNA suggests several possibilities; for example, the CNPase protein per se may be more stable than other myelin proteins or its translation and accumulation as a cytoplasmic protein was less affected by any delay in the development of myelin membranes. The modest, but significant, delay in the recovery of MAG RNA at P15 (Table 1) could have contributed to the reduction in protein at P30. A greater dependence on translational control may account for the observed change in PLP protein at P30 (Fig. 1).

In addition to analyzing overall myelin protein and RNA expression, the number of mature $\left(\mathrm{CC}^{+}\right)$and mature myelinating $\left(\mathrm{CC}^{+} \mathrm{MAG}^{+}\right)$oligodendrocytes was quantified at various developmental time points. In agreement with our previous findings (Schmitz et al., 2011), the number of $\mathrm{CC}^{+}$oligodendrocytes increased over time in both experimental groups, but there were significantly less $\mathrm{CC}^{+}$oligodendrocytes at $\mathrm{P} 8$ and $\mathrm{P} 10$, with numbers returning to control levels by P12 (Fig. 1C,D). However, the number of $\mathrm{CCl}^{+} \mathrm{MAG}^{+}$oligodendrocytes remained significantly reduced at P12, P15, and P30 in the hyperoxic group of animals (Fig. 1C,D).

These results indicate that, first, despite rapid recovery in the total number of mature oligodendrocytes $\left(\mathrm{CC}^{+}\right.$cells), myelin protein levels (specifically MAG and PLP) remain diminished throughout development, not recovering until P60. Second, the number of $\mathrm{CC}^{+}{ }^{+} \mathrm{MAG}^{+}$cells is also decreased throughout de- 

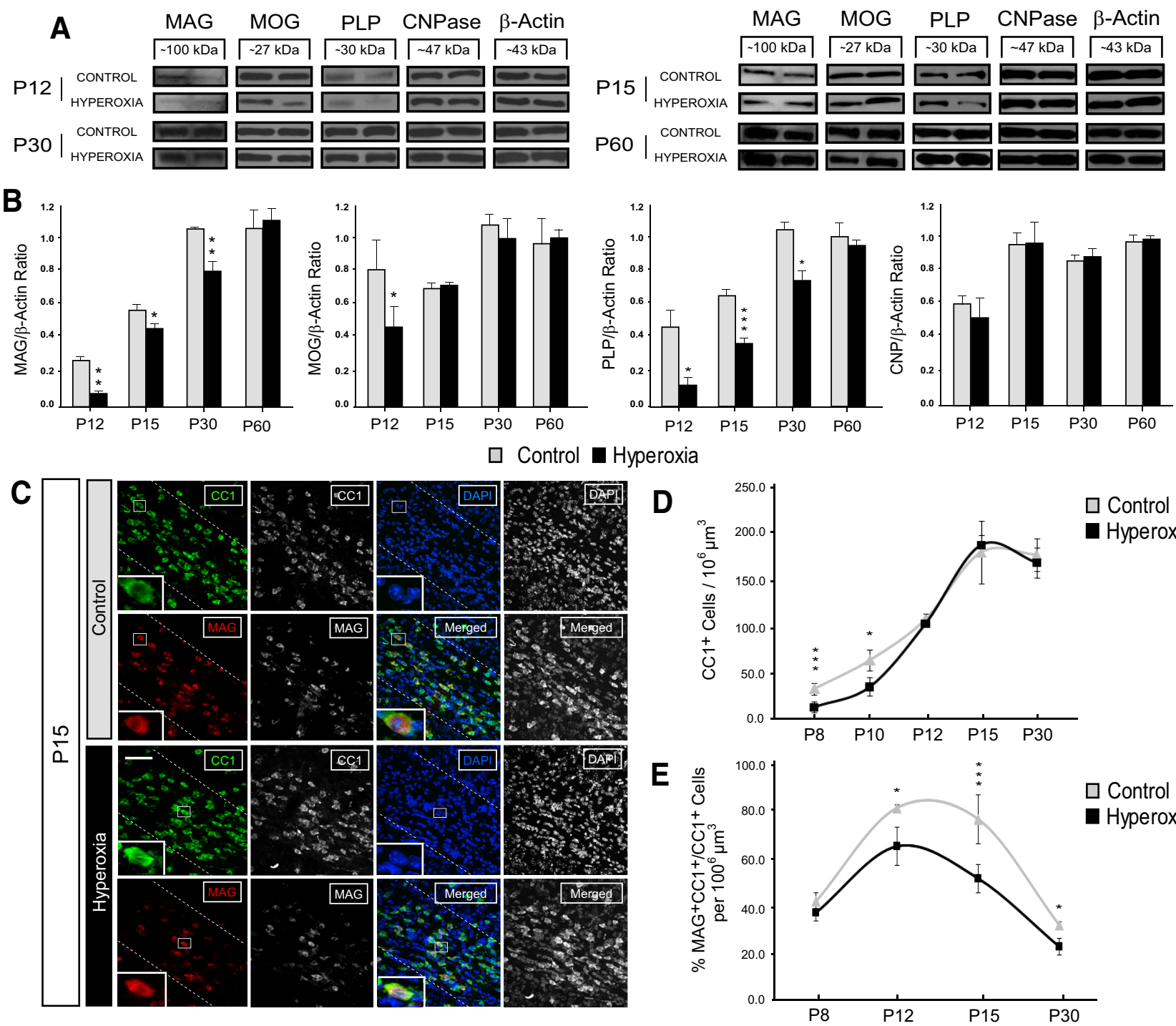

Figure 1. Neonatal hyperoxia causes a selective decrease in myelin protein expression during WM myelination. MAG and PLP expression along with the number of MAG ${ }^{+} \mathrm{CC} 1^{+}$oligodendrocytes were decreased throughout WM development in the hyperoxic group. $A$, Representative Western blots for each MAG, MOG, PLP, and CNPase at P12, P15, P30, and P60. B, Quantification of myelin protein expression for each respective myelin protein at P12, P15, P30, and P60. A pairwise comparison between the control versus the hyperoxia group was conducted for each protein of interest at all time points. C, Images of $\mathrm{MAG}^{+} \mathrm{CC} 1^{+}$oligodendrocytes at P15. The number of $\mathrm{MAG}^{+} \mathrm{CC}^{+}$cells was significantly lower in the hyperoxic group with no change in the number of $\mathrm{CC} 1^{+}$cells. $D$, Number of $\mathrm{CC}^{+}{ }^{+}$oligodendrocytes found in the WM throughout development in control versus hyperoxia. $E$, Percentage of $\mathrm{CC}^{+}{ }^{+}$oligodendrocytes that are immunopositive for MAG at P8, P12, $\mathrm{P} 15$, and $\mathrm{P30}$. The number of $\mathrm{MAG}^{+} \mathrm{CC}{ }^{+}$cells was significantly lower in the hyperoxic group with no change in the number of $\mathrm{CC} 1^{+}$cells. Scale bar, $50 \mu \mathrm{m}$. Data are shown as mean $\pm \mathrm{SD}(n=$ $3-6$ brains for each group, unpaired $t$ test control vs hyperoxia; ${ }^{*} p<0.05,{ }^{* *} p<0.025,{ }^{* * *} p<0.005$ ).

Table 1. Myelin RNA values after neonatal hyperoxia exposure

\begin{tabular}{cccc}
\hline & \multicolumn{3}{c}{ Postnatal age } \\
\cline { 2 - 4 } Myelin gene & P12 & P15 & P30 \\
\hline MBP & $0.520 \pm 0.060^{* *}$ & $1.073 \pm 0.082$ & $1.067 \pm 0.163$ \\
PLP & $0.322 \pm 0.065^{* *}$ & $0.943 \pm 0.113$ & $1.038 \pm 0.118$ \\
CNP & $0.526 \pm 0.061^{* *}$ & $0.753 \pm 0.130$ & $0.934 \pm 0.110$ \\
MAG & $0.447 \pm 0.010^{* *}$ & $0.737 \pm 0.069^{*}$ & $0.995 \pm 0.120$ \\
M0G & $0.356 \pm 0.053^{* *}$ & $0.95 \pm 0.188$ & $0.998 \pm 0.027$
\end{tabular}

Relative abundance of myelin RNA from WM tissue sampled at different times after hyperoxia expressed as a ratio over age-matched room air controls. Data are shown as means \pm SEM. ${ }^{*} p<0.05$, ${ }^{* *} p<0.001$, unpaired Student's $t$ test comparing hyperoxia versus control ( $n=4-5$ in all groups, including controls).

velopment in animals exposed to hyperoxia. This indicates a change in the ability of differentiating oligodendrocytes of the maturing WM to produce specific myelin proteins, which may ultimately alter developmental myelination.
Mice exposed to neonatal hyperoxia exhibit a reduction in myelin thickness, abnormal myelin loops, and decreased axonal caliber during WM development

Several myelin protein knock-out and mutant mice exhibit myelin and axonal abnormalities. MAG-null mice are able to synthesize myelin normally, but display dysmyelination (Yin et al., 1998; Pan et al., 2005), decreased axon caliber (Yin et al., 1998; Pan et al., 2005), and axonal degeneration (Pan et al., 2005). PLP knock-outs and mutants exhibit a condensed intraperiod line in the CNS, but myelin synthesis appears to be normal (Campagnoni and Skoff, 2001). Adult PLP knock-out mice also show a significant amount of axonal degeneration, revealing an important role for PLP in axon integrity (Campagnoni and Skoff, 2001).

The observation that mice exposed to neonatal hyperoxia exhibited a reduction in MAG and PLP protein expression in the $\mathrm{WM}$ and a decrease in these myelin proteins at several time points 
A

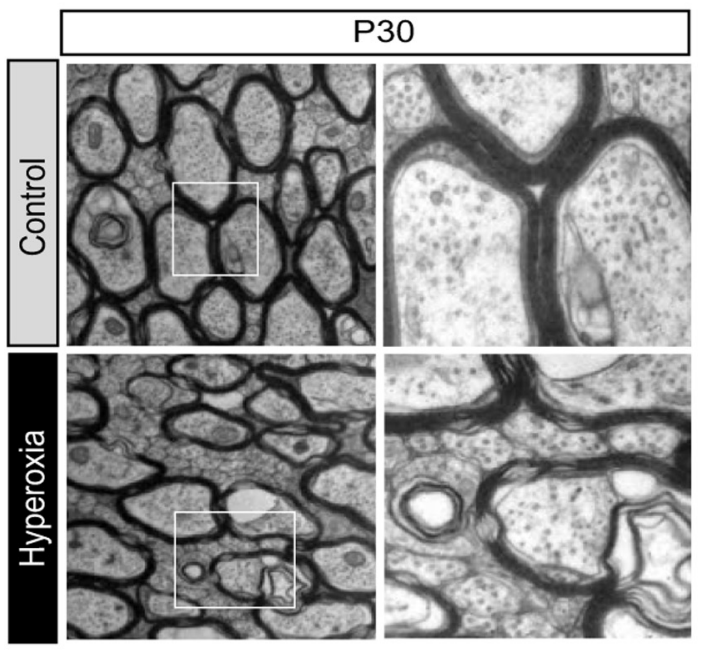

C

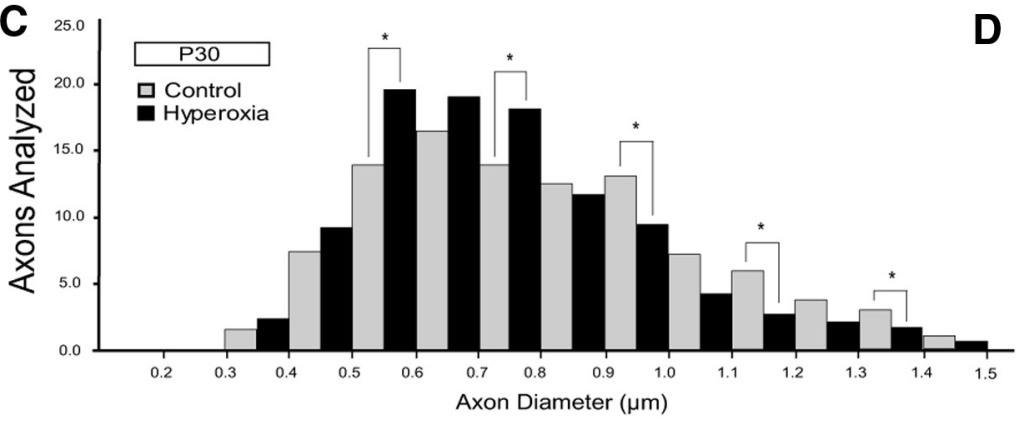

B
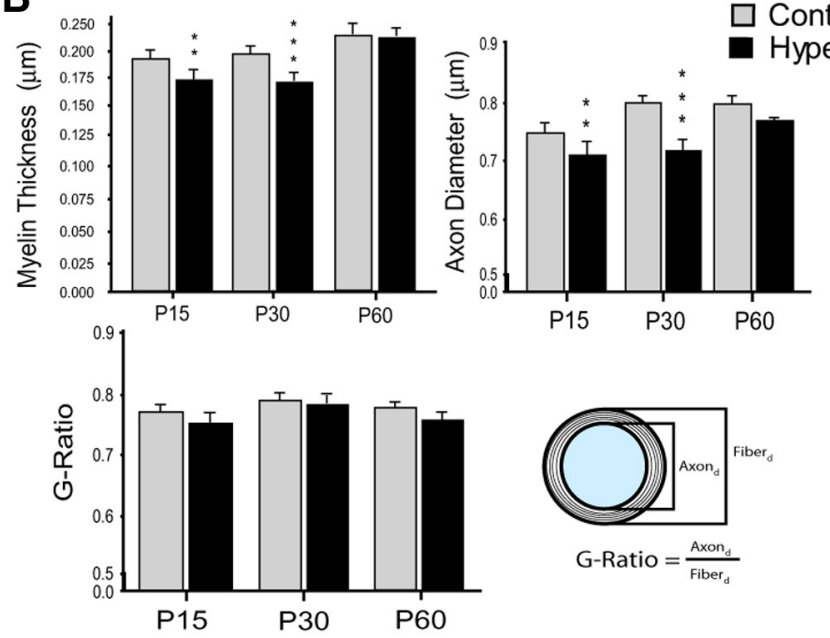

$\square$ Control
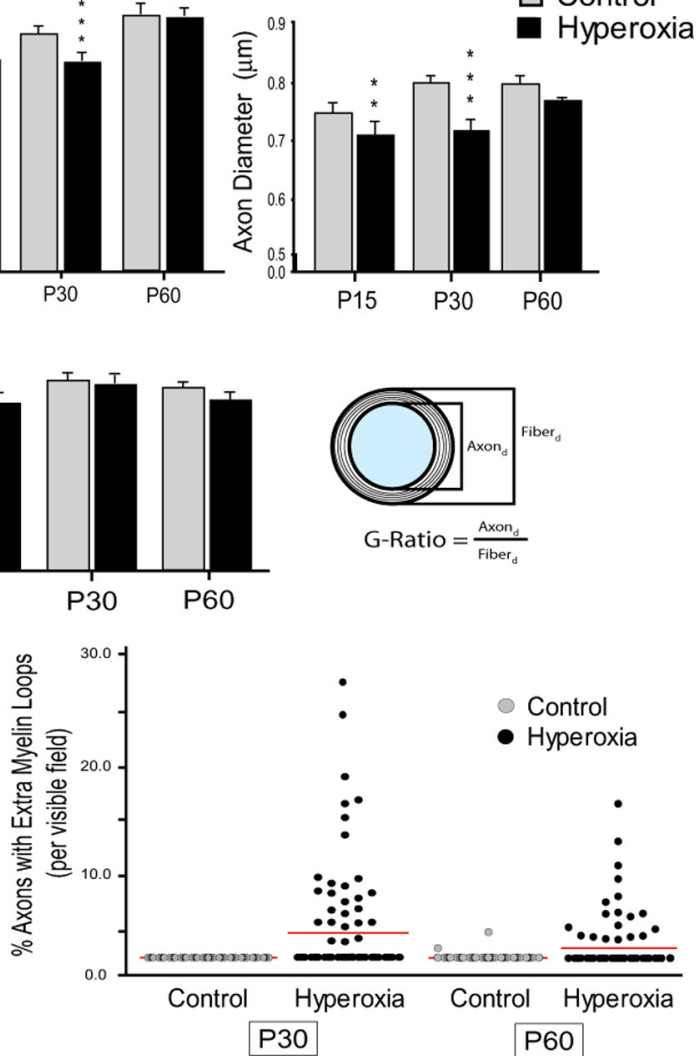

E
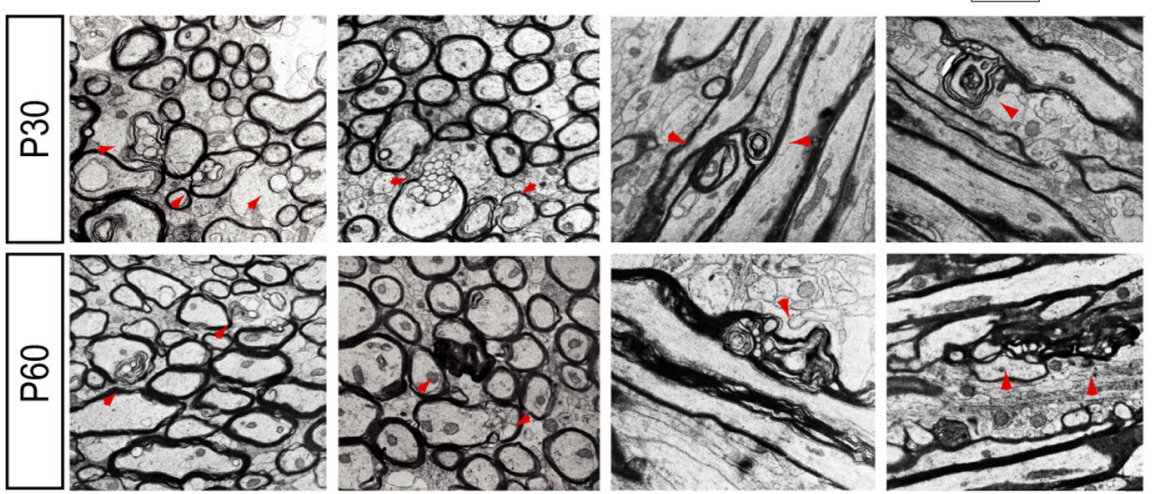

Figure 2. Mice exposed to neonatal hyperoxia exhibit decreased myelin thickness and axon caliber during WM development. $A$, Representative electron microscopy images at P30 displaying decreases in both myelin thickness and axon caliber in mice exposed to neonatal hyperoxia. Images were taken at a magnification of $10,000 \times$. $\boldsymbol{B}$, Histograms displaying mean myelin thickness, axon caliber, and g-ratio in the hyperoxia exposed group versus controls at P15, P30, and P60. The g-ratio was calculated as the axon diameter divided by the fiber diameter (diameter of axon + myelin). C, Distribution of axon caliber for hyperoxia versus control groups at P30. D, Percentage of axons with extramyelin loops at P30 and P60. Red lines represent mean percentage for each respective group and time point. $E$, Extramyelin loops and myelin outfolding examples taken from both P30 and P60 animals exposed to neonatal hyperoxia. Images were taken at a magnification of $16,000 \times$. Data are shown as mean \pm SD ( $n=3-5$ brains for each group, using a Mann-Whitney rank sum test comparing control vs hyperoxia, $\left.{ }^{*} p<0.05,{ }^{* *} p<0.025,{ }^{* * *} p<0.005\right)$.

during developmental myelination (Fig. 1) suggests that changes in myelin thickness and axon caliber may be observed with electron microscopy. In addition, the g-ratio was calculated to determine the relationship between axon size and the degree of axonal myelination.

Mice exposed to neonatal hyperoxia exhibited a significant decrease in mean myelin thickness at P15 and P30 (Fig. 2 A, B; P15 control $0.190 \pm 0.004 \mu \mathrm{m}, \mathrm{P} 15$ hyperoxia $0.174 \pm 0.006 \mu \mathrm{m} ; \mathrm{P} 30$ control $0.196 \pm 0.003 \mu \mathrm{m}, \mathrm{P} 30$ hyperoxia $0.187 \pm 0.003 \mu \mathrm{m})$. These same mice analyzed also showed a marked decrease in mean axon caliber at P15 and P30 (Fig. 2A,B; P15 control $0.758 \pm 0.015 \mu \mathrm{m}, \mathrm{P} 15$ hyperoxia $0.725 \pm 0.012 \mu \mathrm{m}$; P30 control $0.812 \pm 0.010 \mu \mathrm{m}, \mathrm{P} 30$ hyperoxia $0.739 \pm 0.013 \mu \mathrm{m})$. The change in axon caliber at P30 is evident from the overall distribution of axon diameters within the $\mathrm{CC}$ at $\mathrm{P} 30$ in the hyperoxia compared with the control groups (Fig. 2C). A higher percentage of smaller axons were found in the hyperoxia group and a greater percentage of larger axons were found in the control group (Fig. 2C). Interestingly, at $\mathrm{P} 60$, no difference was detected in mean myelin thickness or mean axon caliber between the two groups (Fig. $2 B$ ). When comparing the g-ratios $\left(\right.$ axon $_{\text {diameter }} /$ fiber $\left._{\text {diameter }}\right)$ of the two experimental groups, no significant difference was detected at any time point analyzed (Fig. 2B). No difference was observed between the two experimental groups in the total number of callosal axons at P15, P30, or P60 (data not shown), suggesting that neurodegeneration is not present in WM axons after neonatal hyperoxia exposure. 
In the process of analyzing myelin ultrastructure, an abnormal number of myelin outfoldings and extra loops at P30 and P60 was observed in mice exposed to neonatal hyperoxia. The percentage of myelinated axons with such loops was quantified and the phenotype found to be significantly more pronounced in the hyperoxia groups at both P30 and P60 (Fig. 2 D,E), with some of these abnormalities occurring at the paranodal regions of myelinated axons. The loops were not observed at P15, so the formation of these myelin anomalies began during developmental myelination between P15 and P30, a time period when a decrease in MAG and PLP expression was observed (Fig. $1 A, B$ ), suggesting the importance of these myelin proteins in the myelination process.

This analysis reveals that oxygen toxicity during a significant phase of brain development disrupts proper myelination and axon radial growth in the subcortical WM. Despite the finding that myelin protein expression, myelin thickness, and axon diameter return to control levels by $\mathrm{P} 60$, the developmental delay in these parameters may have produced lasting effects on axonal structure and function. Therefore, axon structure, organization, and function were analyzed.

\section{NF phosphorylation is altered after neonatal hyperoxia exposure}

NFs are the predominant structural component of the adult neuronal cytoskeleton and can be subdivided into three distinct classes: (1) NF light (NF-L, $\sim 68 \mathrm{kDa}$ ), (2) NF medium (NF-M, $\sim 160 \mathrm{kDa}$ ), and (3) NF heavy (NF-H, $\sim 200 \mathrm{kDa}$ ) (Perrot et al., 2008). These three NFs interact to form type IV intermediate filaments $(10 \mathrm{~nm})$. The expression of NFs increases in maturing neurons and the assembly of new NFs involve the phosphorylation of many Ser and Thr residues (Perrot et al., 2008). Evidence exists that properly ensheathed axons have larger diameters, likely due to increased NF phosphorylation (Kirkpatrick and Brady, 1999; Sánchez et al., 2000; Quarles et al., 2006). In addition, MAG knock-outs not only exhibit dysmyelination and reduced axon calibers (Yin et al., 1998; Pan et al., 2005), they also display decreased NF spacing (Yin et al., 1998; Pan et al., 2005) and NF phosphorylation (Yin et al., 1998; Pan et al., 2005). Therefore, total NF (NF-H/NF200), phosphorylated NF (SMI31 ), and nonphosphorylated NF (SMI-32) expression and phosphorylation were analyzed to assess the impact of hyperoxia exposure on proteins that regulate axon radial expansion under normal physiological conditions.

When total NF200 expression was determined using Western blot analysis of microdissected WM tissue, no significant change was observed between the hyperoxia and control groups at any developmental time point (Fig. 3A-E). However, when the total SMI-31 and fractional SMI-31 (SMI-31/NF200) were quantified, a significant decrease was found at both P12 and P15, with protein expression returning to control levels by P30 (Fig. 3A-E) and P60 (data not shown). The changes in total and fractional SMI-32 showed a trend opposite to that of SMI-31. Protein levels of SMI-32 were increased by hyperoxia at P12 and P15, returning to control levels by P30 (Fig. $3 A-E$ ) and P60 (data not shown). Immunofluorescence of NF200, SMI-31, and SMI-32 revealed an expression pattern similar to that found by Western blot analysis (Fig. 3B). Despite the changes in NF phosphorylation, little to no axon degeneration, as measured by $\beta$-amyloid-positive immunofluorescence, was observed in either group at any time point analyzed (data not shown).

NFs enhance axon caliber and a positive correlation exists between axonal diameter and myelin thickness, action potential amplitude, and conduction velocity in myelinated axons (Perrot et al., 2007). The changes observed in NF phosphorylation are evident during a critical period in WM development, when the myelination of maturing axons is important for their radial expansion. This raises the possibility that altered developmental myelination in the WM affects overall axonal integrity. These differences may also reflect changes in axonal cytoarchitecture that may lead to chronic axonal dysfunction.

\section{Neonatal hyperoxia causes lasting changes in axonal paranode and node of Ranvier organization}

Saltatory conduction involves the propagation of action potentials along myelinated axons. These electrical signals require the correct structure and function of each axonal segment and the myelinated axon contains specific domains that are molecularly and functionally distinct from one another (Poliak and Peles, 2003).

During development, a large number of sodium $\left(\mathrm{Na}^{+}\right)$channels cluster at the nodes of Ranvier. The segment adjacent to the nodes of Ranvier, the paranodal region, contains the initial axonoligodendrocyte junction. During the process of axon wrapping, the oligodendrocyte contacts the axon many times along the paranodal region forming compact myelin. The interaction between the axon and the oligodendrocyte at the paranodal region involves several important proteins. MAG, present on the cell membrane of the myelinating oligodendrocyte, is thought to be involved in the initiation and maintenance of the myelinated axon (Schnaar and Lopez, 2009). MAG ${ }^{-1-}$ mice are able to form a paranodal region (Marcus et al., 2002); abnormalities appear to exist on the paranodal segment (Yin et al., 1998). PLP mutants also exhibit disturbances in the formation of the paranodal region on myelinated axons in the PNS and CNS (Tanaka et al., 2009). Therefore, it appears that proper developmental myelination is necessary for the creation of the paranodal segment.

Contactin-1 and Caspr are expressed on the axonal side. Caspr is a transmembrane protein from the family of neurexins that function as cell adhesion proteins. The interaction of contactin and Caspr is necessary for the complex to be transported to the cell membrane (Poliak and Peles, 2003).

To assess the effect of hyperoxia on paranode organization, the number and distribution of Caspr pairs was determined. Throughout development, from P12 to P60, the number of Caspr pairs was decreased by hyperoxia (Fig. $4 A, D$ ). In addition, the distance between Caspr pairs increased and the Caspr spread decreased after hyperoxia (Fig. 4B,C). The mean distance between Caspr pairs (nodes of Ranvier) was also significantly larger in the animals exposed to neonatal hyperoxia at all developmental time points (Fig. $4 B, D$ ). When the Caspr spread was analyzed, a significant decrease was found in the mean distribution of Caspr immunofluorescence in the hyperoxia group compared with controls at P15, P30, and P60 (Fig. 4C,D). Representative histograms shown in Figure $4 E, F$ demonstrate the differences in the distance between Caspr pairs and the Caspr spread in the WM of hyperoxia versus control groups at P30.

In addition to $\mathrm{Na}^{+}$channel clustering, the proper distribution of $\mathrm{Na}^{+}$channels at the nodes of Ranvier is also necessary for efficient action potential propagation, and the paranodal region is thought to play an important role in determining the size and composition of the nodes of Ranvier (Rios et al., 2003). Therefore, we analyzed intact nodes of Ranvier by quantifying the number of Caspr pairs that were associated with Nav1.6 immunofluorescence. A significant decrease in the total number of detectable Caspr/Nav1.6 pairs was observed at both P30 and P60 in mice exposed to neonatal hyperoxia (Fig. $5 A, B$ ). The percentage 
A

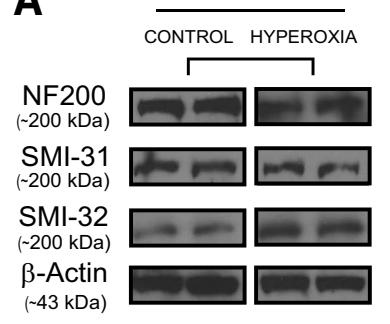

B

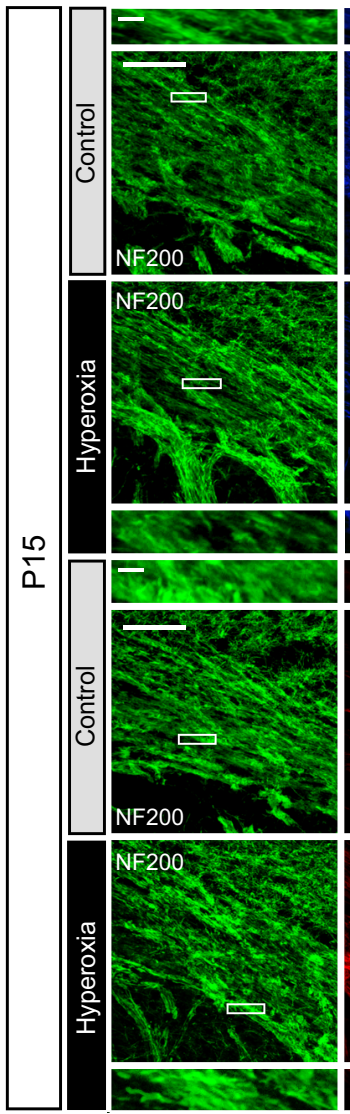

P15

CONTROL HYPEROXIA
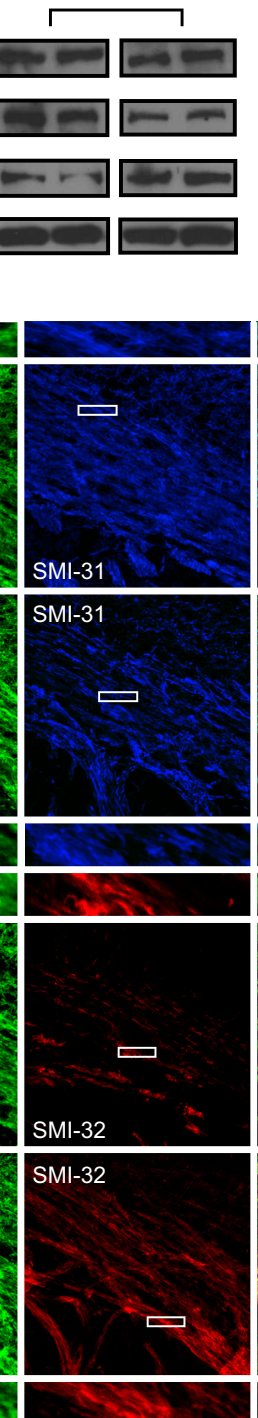

P30

CONTROL HYPEROXIA
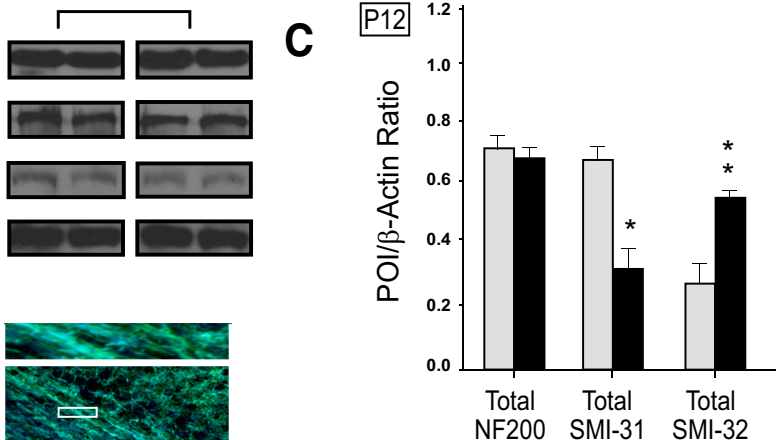

D
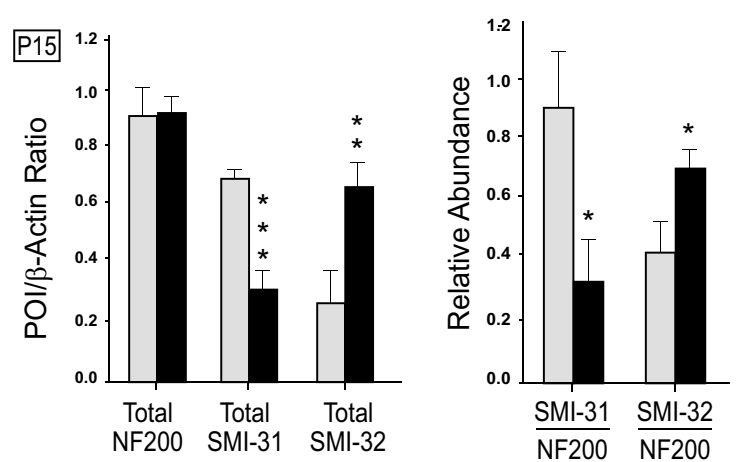

E

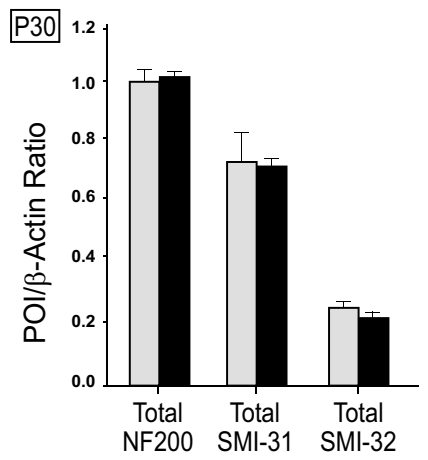

Hyperoxia
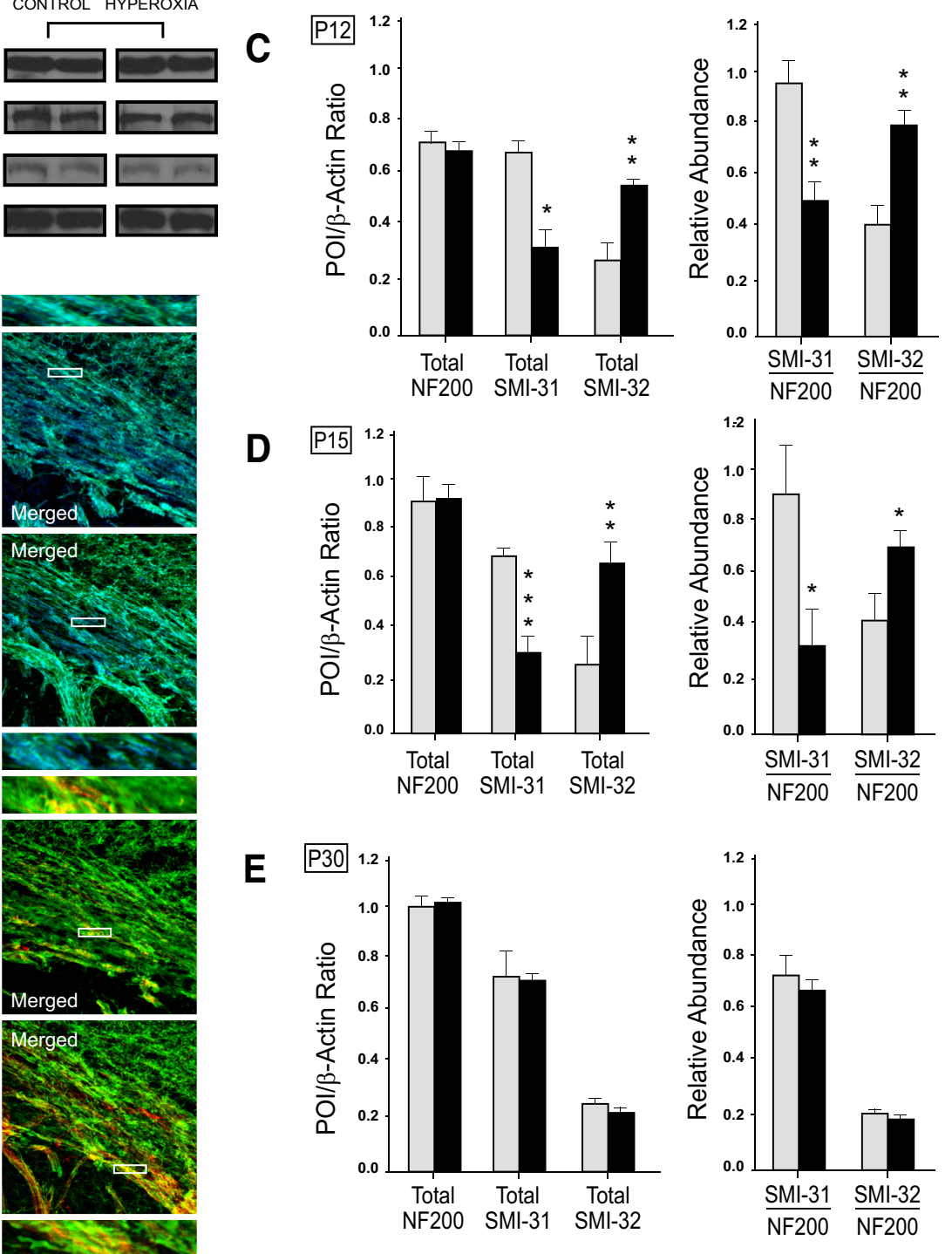

Figure 3. NF phosphorylation is altered after neonatal hyperoxia exposure. $A$, Representative Western blots for the NFs NF200, SMI-31, and SMI-32 at P12, P15, and P30. A pairwise comparison between the control versus the hyperoxia group was conducted for each protein of interest at all time points. B, Confocal images of NF200, SMI-31, and SMI-32 at P15 in control versus hyperoxic mice. Small scale bar, $50 \mu \mathrm{m}$; large scale bar, $25 \mu \mathrm{m}$. C-E, Quantification of the total amount of protein expression for each NF and the ratios of SMI-31/NF200 and SMI-32/NF200 at P12, P15, and P30. No significant difference was observed in NF200 expression. However, SMI-31 expression was decreased and SMI-32 increased at P12 and P15; both returned to control levels by P30. Data are shown as mean $\pm S D\left(n=3-5\right.$ brains for each group, unpaired $t$ test, control vs hyperoxia; ${ }^{*} p<0.05,{ }^{* *} p<0.025,{ }^{* * *} p<0.005$ ).

of Caspr/Nav1.6 to Caspr pairs did not change at either time point (Fig. $5 C$ ). When analyzing the dispersion of Nav1.6 channels along the nodes of Ranvier, the hyperoxic group displayed a mean increase in Nav1.6 immunofluorescence spread at both P30 and P60 (Fig. 5D).

The changes in the number of Caspr and Caspr/Nav1.6 pairs observed in the hyperoxia group reveal a relationship between altered WM development/myelination and a disruption in WM axonal domain organization, specifically at the paranode and nodes of Ranvier. Furthermore, these analyses provide evidence that an increased mean nodal length likely arose from altered paranodal regions. This suggests that the size of the paranodal domain, not merely its presence, plays a direct role in the distribution of Nav1.6 channels along the nodes of Ranvier.
Neonatal hyperoxia exposure alters electrophysiological properties of the WM

To characterize the functional consequences of hyperoxiainduced structural changes to myelination and axon-oligodendrocyte interaction, CAPs were recorded from CC brain slices at P30 and P60 (Fig. 6A). CAPS are electrophysiological field recordings that measure the conduction properties of a designated region of the brain and have been used in other models of WM injury (Aguirre et al., 2007; Crawford et al., 2009). After the initial stimulus, CAPs display two subsequent downward waves, with the first representing the rapidly conducting $\mathrm{M}$ axons and the second being the more slowly responding fibers, which consist of predominately UM axons. The parameters analyzed in the hyperoxia and control groups included both the maximal amplitude (in millivolts) and the 

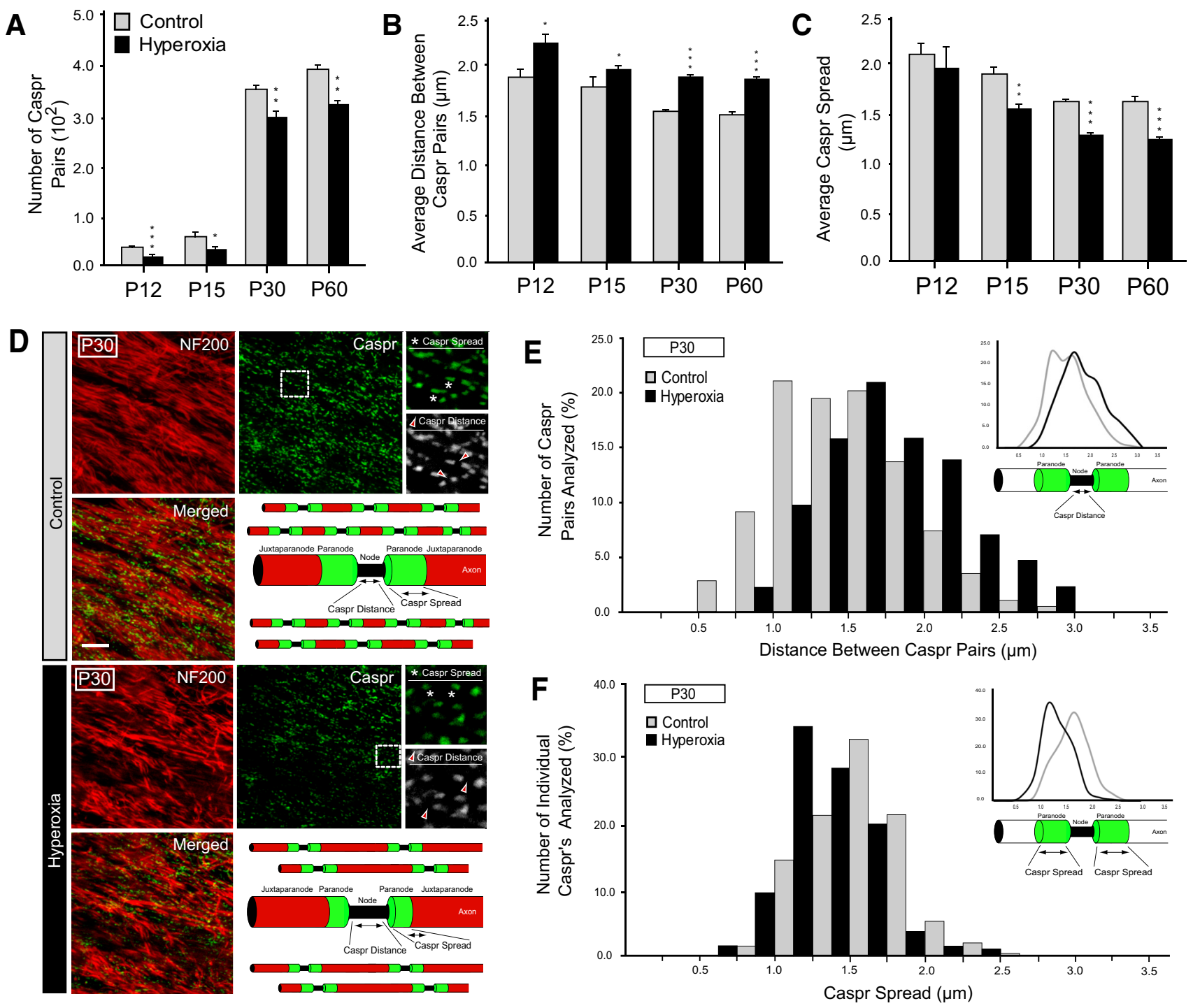

Figure 4. Caspr pair number and distribution are modified after neonatal hyperoxia exposure. $A$, Total number of Caspr pairs in the WM in hyperoxia versus control. At each developmental time point (P12, P15, P30, and P60), the number of Caspr pairs was significantly less in the hyperoxia group. B, C, Histograms displaying the mean Caspr distance and Caspr spread at P12, P15, P30, and $\mathrm{P} 60$, respectively. The average Caspr distance was significantly increased at all time points and the Caspr spread was decreased at P15, P30, and P60. D, Representative confocal images of Caspr and NF200 at P30 showing a decrease in the number of Caspr pairs and the changes to the Caspr distance and spread. Scale bar, $50 \mu \mathrm{m}$. E, F, Distributions of Caspr distance and Caspr spread at P30, respectively. Data are shown as mean $\pm S D\left(n=3-4\right.$ brains for each group, unpaired $t$ test, control vs hyperoxia; ${ }^{*} p<0.05,{ }^{* *} p<0.025$, $\left.{ }^{* * *} p<0.005\right)$.

conduction velocities (in milliseconds) of both the M and UM waves.

At P30, the mean amplitude of the hyperoxia group for the $\mathrm{M}$ wave was $0.078 \mathrm{mV}$ and for the $\mathrm{UM}$ wave was $0.209 \mathrm{mV}$, a significant decrease from the control group, which demonstrated an M wave amplitude of $0.350 \mathrm{mV}$ and an UM wave amplitude of 0.559 $\mathrm{mV}$, respectively (Fig. $6 B-D$ ). A similar change was observed at P60 (Fig. 6D,E; control M mean, $0.446 \mathrm{mV}$; control UM mean, $0.638 \mathrm{mV}$; hyperoxia M mean, $-0.197 \mathrm{mV}$; hyperoxia UM mean, $0.356 \mathrm{mV}$ ). When comparing conduction velocities of the $\mathrm{M}$ waves at P30, the animals exposed to neonatal hyperoxia had a $60 \%$ slower time to peak amplitude than controls (Fig. $6 \mathrm{~F}$ ). At $\mathrm{P} 60$, conduction velocity of the hyperoxia $\mathrm{M}$ wave was found to be still 30\% less than controls (Fig. 6F). A significant difference in conduction velocity of the UM wave was detected at P30, but not at P60 (Fig. 6G).

These findings indicate that callosal WM axons in animals exposed to neonatal hyperoxia exhibit persistent changes in their electrophysiological properties. In M axons, changes were present at both time points analyzed with respect to amplitude and velocity. A significant difference in amplitude was observed in $\mathrm{UM}$ at both time points; however, at P60, a change was only observed in conduction amplitude, not velocity. These deficits include changes in the speed and degree of axonal action potential propagation, properties affected by myelin compactness, axon caliber, and axon organization.

\section{Discussion}

Preterm delivery increases oxygen tension (Weber and Secher, 1979; Castillo et al., 2008) and oxidative stress (Davis and Auten, 2010) in the premature infant with reduced antioxidant capacity (Georgeson et al., 2002). Previous studies have demonstrated that neonatal oxygen toxicity in rodents disrupts WM development through immature oligodendroglial cell death and delayed lineage maturation (Felderhoff-Mueser et al., 2004; Gerstner et al., 2008; Schmitz et al., 2011) and revealed functional differences 
A
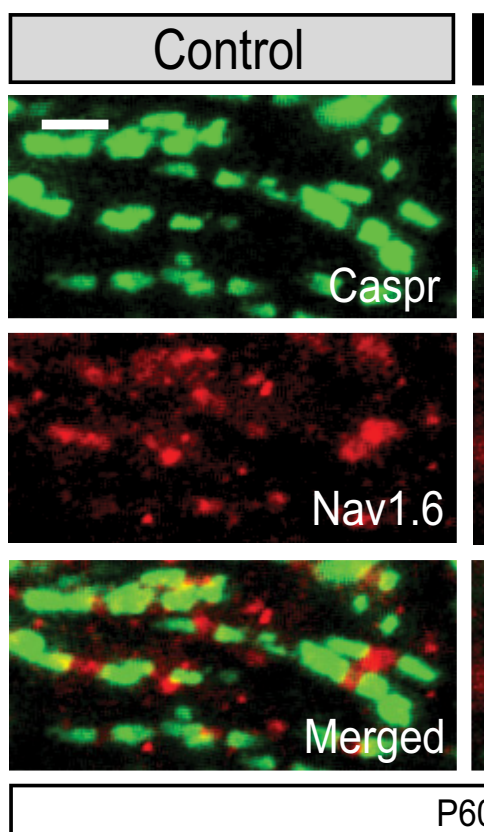
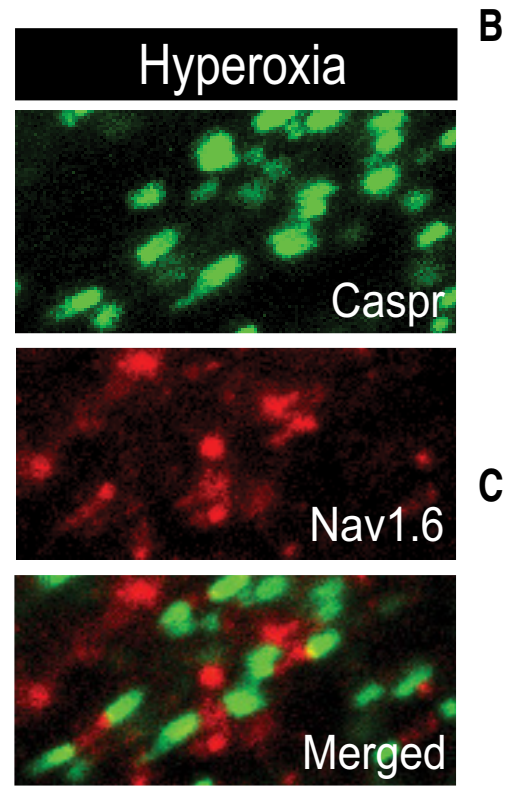

$\mathrm{P} 60$
B

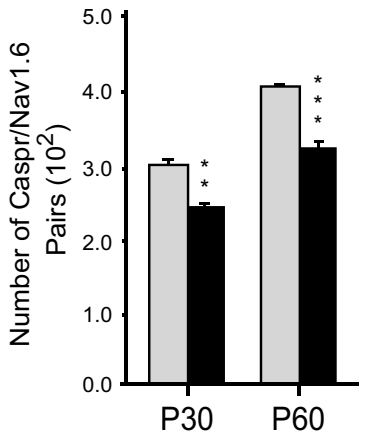

C

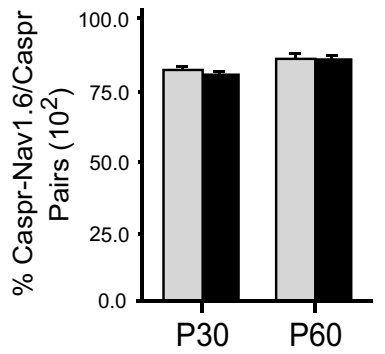

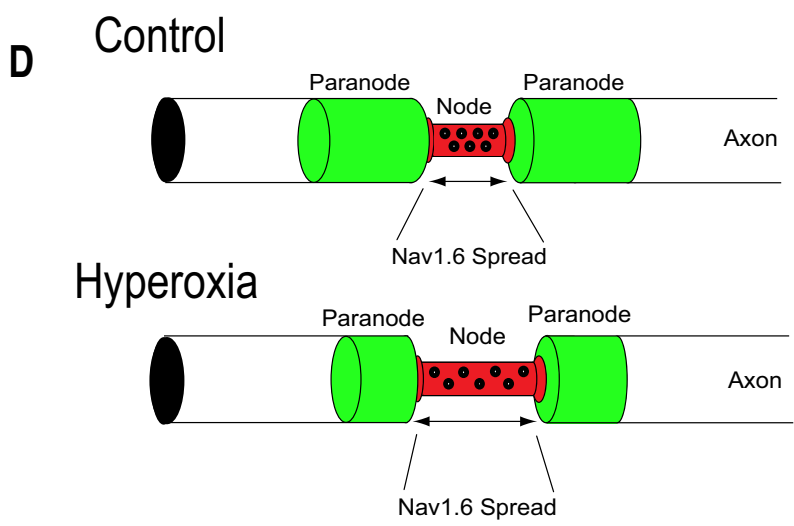

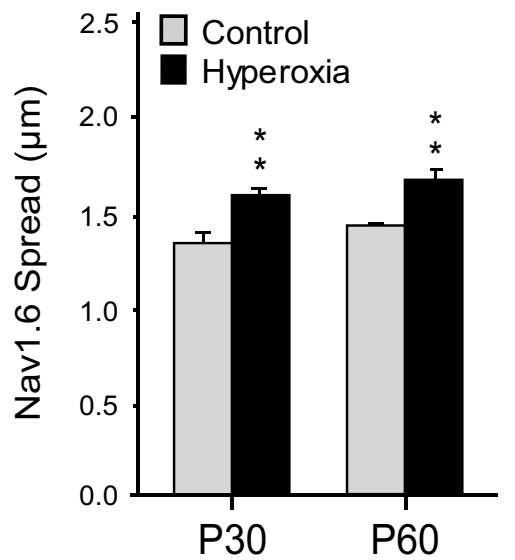

Figure 5. Neonatal hyperoxia exposure alters axonal nodes of Ranvier in the developing and mature WM. A, Representative confocal images of Caspr and Nav1.6 at P60 showing a decrease in the number of Caspr/Nav1.6 pairs and the change in the distribution of Nav1.6 immunofluorescence. Scale bar, $5 \mu \mathrm{m}$. B, Graph displaying the significant decrease in the number of Caspr/Nav1.6 pairs between hyperoxia and control groups at P30 and P60. C, Histogram comparing control versus hyperoxia groups at P30 and P60 for the percentage of Caspr-Caspr/Nav1.6 pairs. D, Diagram of data shown in graph to the right. The distribution of Nav1.6 channels along the nodes of Ranvier is more widely dispersed in animals exposed to neonatal hyperoxia. Data are shown as mean \pm SD $(n=$ $3-4$ brains for each group, unpaired $t$ test, control vs hyperoxia; ${ }^{*} p<0.05,{ }^{* *} p<0.025$, ${ }^{* * *} p<0.005$ ).

between hyperoxia- and hypoxia-induced injury (Ramani et al., 2013). The use of $80-85 \%$ oxygen in rodent hyperoxia models, which consistently causes detectable brain injury, is significantly higher than levels for oxygen therapy in respiratory distress (Castillo et al., 2008; Bancalari and Claure, 2012). However, during resuscitation from cardiac arrest in children, target oxygen levels remain a concern (Ferguson et al., 2012; Guerra-Wallace et al., 2013).

In the present study, we show that the pathogenesis of hyperoxia-induced WM injury in the neonatal mouse involves a disruption in the axon-oligodendrocyte interaction, which leads to functional impairment in adulthood. Exposure to high amounts of oxygen causes oligodendrocyte dysfunction during WM development, with myelination abnormalities and axonopathy being present in vivo. These changes in axon-oligodendrocyte interactions include: (1) reduced myelin thickness, (2) decreased axon caliber, (3) diminished NF phosphorylation, and (4) extramyelin loops/delamination. Despite the recovery of many of these properties in the adult WM, the myelinated axons of animals exposed to neonatal hyperoxia continued to display pathology at both the paranodal region and the nodes of Ranvier. Ultimately, these axonal domain abnormalities are responsible for a reduction in the conduction properties of axons projecting through the subcortical WM. The discovery that neonatal hyperoxia exposure in the rodent causes lasting changes in axon-oligodendrocyte integrity represents an important finding in our understanding of hyperoxia-induced WM injury in the prematurely born infant.

\section{The relationship between oligodendrocyte dysfunction and} WM axon ultrastructure

Myelination has been shown to play a neuroprotective role, because axonal loss is found in several demyelinating disorders, including multiple sclerosis, leukodystrophies, and CharcotMarie-Tooth neuropathy (Nave, 2010; Piaton et al., 2010). It is also thought to play a significant role in overall axonal integrity 

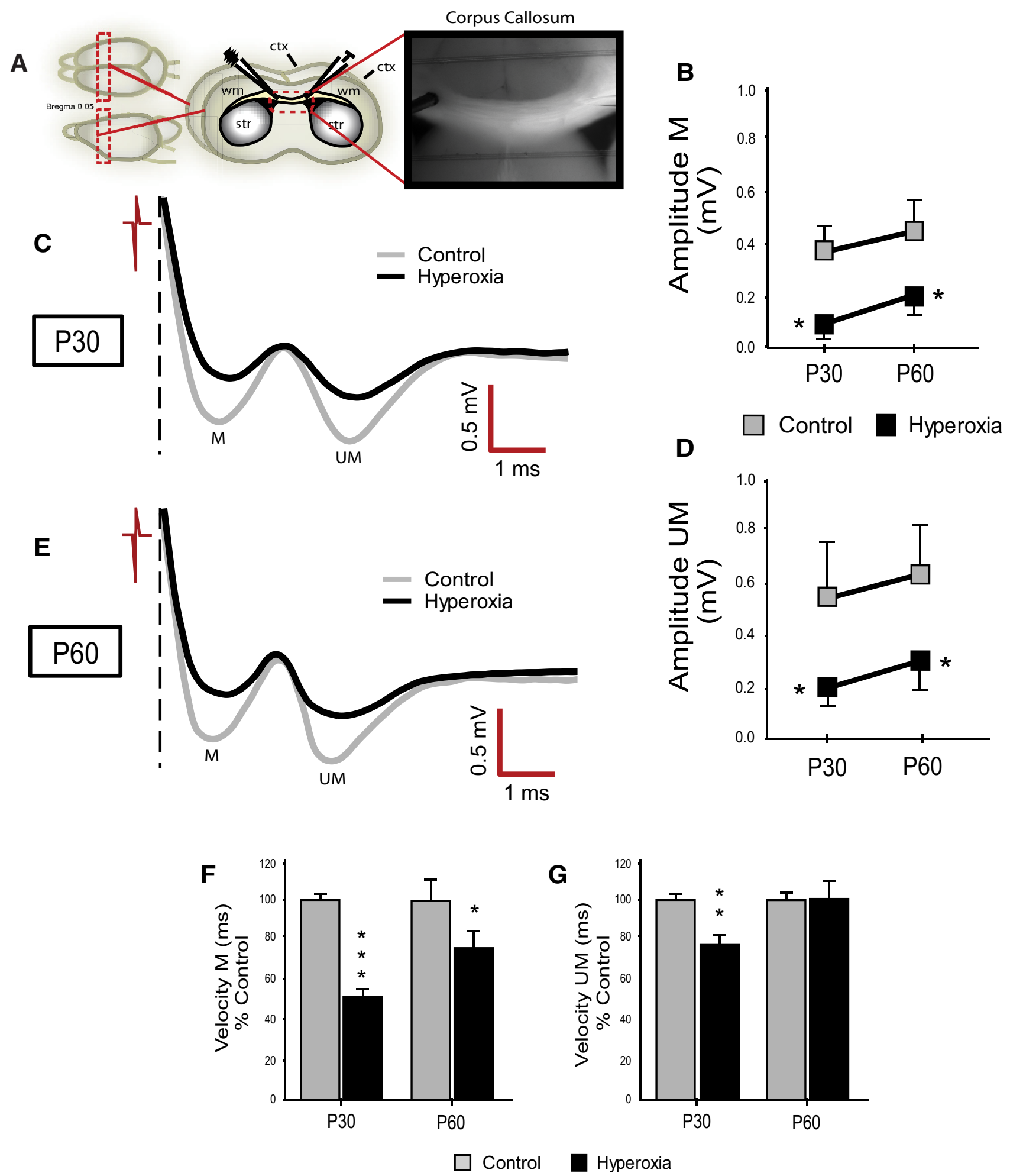

Figure 6. Changes in CAP recordings after neonatal hyperoxia exposure. $A$, Diagram demonstrating the placement of the stimulating and recording electrodes for $C A P$ recordings in the $C C$ of the WM. $B$, Graph displaying the significant decrease in mean amplitude of the $M$ wave between hyperoxia and control groups at $P 30$ and P60. C, Representative trace of CAP recordings for control versus hyperoxia groups at $\mathrm{P} 30$. Each recording contained a rapid $\mathrm{M}$ wave and a slower UM wave. $\boldsymbol{D}$, Graph showing the significant decrease in mean amplitude of the UM wave in hyperoxia and control group at $\mathrm{P} 30$ and P60. $\boldsymbol{E}$, Representative trace of CAP recordings for control versus hyperoxia groups at P60. $\boldsymbol{F}$, Histograms demonstrating the mean velocity of the M waves, represented by percentage of control for each group at P30 and P60. G, Histograms demonstrating the mean velocity of the $\mathrm{M}$ waves, represented by percentage of control for each group at P30 and P60. Data are shown as mean $\pm S D\left(n=5\right.$ brains for each group, Mann-Whitney rank-sum test, control vs hyperoxia; $\left.{ }^{*} p<0.05,{ }^{* *} p<0.025,{ }^{* * *} p<0.005\right)$. 
and function of surviving neurons (Simons and Trajkovic, 2006; Nave and Trapp, 2008; Nave, 2010). It is currently unclear how premature WM injury affects overall axonal integrity. In the present study, we found no evidence of gross neurodegeneration or atrophy at any time point analyzed.

MAG, a myelin protein expressed specifically by oligodendrocytes, is involved in the initiation and maintenance of myelinated axons (Schnaar and Lopez, 2009). We found a disruption in developmental myelination and a decrease in select myelin proteins (MAG and PLP) throughout WM development. Despite generalized decreases in the RNA of multiple myelin genes shortly after hyperoxia, a rapid return of steady-state RNA to control levels, with the exception of MAG RNA, was observed by P15, suggesting the possibility of posttranscriptional events such as translational processing and membrane trafficking, which contribute to myelin sheath alterations. We also observed delamination, abnormal myelin loops, and outfoldings in the adult myelin sheaths. These abnormalities in myelin compaction may be attributed to altered PLP (Bakhti et al., 2013) or MAG protein levels. Interestingly, myelin compaction defects were found to be related to changes in MAG and P0 disorders of the PNS (Vital et al., 2003). One possible mechanism that could contribute to these changes in myelin protein expression and incomplete oligodendroglia maturation is altered glutamate homeostasis, which is acutely disrupted after hyperoxia (Schmitz et al., 2011).

Properly myelinated axons have been proposed to have larger calibers and this has been associated with enhanced NF phosphorylation (Kirkpatrick and Brady, 1999; Sánchez et al., 2000; Quarles et al., 2006). NF abnormalities are observed in several neurodegenerative diseases including: amyotrophic lateral sclerosis, Alzheimer's disease, Parkinson's disease, Charcot-Marie-Tooth disease, and toxic neuropathy (Lui et al., 2011). Differential NF expression, stoichiometry, and phosphorylation status in animal models of these diseases reveals the important role that NFs play in axon integrity (Lui et al., 2011).

MAG knock-out mice exhibit decreased NF spacing, reduced NF phosphorylation, and smaller axonal diameters (Yin et al., 1998; Pan et al., 2005). Additional in vivo studies have indicated that MAG causes a direct increase in phosphorylated NFs and is thought to be mediated through the kinases (cdk5 and ERK 1/2) involved in the phosphorylation of NFs (Dashiell et al., 2002). These studies suggest that MAG-mediated signaling is required for proper developmental myelination and axonal integrity. In addition, our observed changes in axon diameter and NF phosphorylation may also be MAG related.

Our analysis suggests that there is a critical time period during WM development at which proper myelination and NF phosphorylation must occur for the "normal" radial growth of axons to take place. If this process does not transpire at the correct moment or for the proper duration, it may have organizational and/or functional consequences for myelinated axons and may ultimately lead to lasting axonopathy.

\section{Myelination and axon domain organization}

Myelination has been associated with nodal, paranodal, juxtaparanodal, and internodal domain formation (Poliak and Peles, 2003). The paranodal region of the myelinated axon appears to be especially sensitive to pathology in the myelin membrane. Tanaka et al. (2009) observed decreased axon diameter, reduced myelin thickness, decreased Caspr distribution at the paranodal region, and abnormal overlap between Caspr and the juxtaparanodal protein/channel Kv1.2 in the CNS of PLP knockout mice. MAG-null mice also exhibit abnormal myelin loops at the paranodal region of the myelinated axon (Yin et al., 1998). Myelinated axons of the subcortical WM in the hyperoxia group exhibited both a decrease in the number of paranodal domains (Caspr pairs) and a mean reduction in the size of the paranodal region at all developmental time points. Our findings reveal an association between the hyperoxia-induced decrease in MAG and PLP protein expression and the formation of abnormal paranodal segments on myelinated axons of the WM.

The paranode domain has been shown to be important for the transition from the Nav1.2 subtype sodium channel to the Nav1.6 subtype sodium channel during development (Rios et al., 2003). Indeed, abnormalities in paranodal and nodal formation are observed after hypoperfusion (Horsburgh et al., 2011; Reimer et al., 2011). In our hyperoxic model, mice also displayed significantly fewer intact nodes of Ranvier, with an overall mean increase in Nav1.6 channel distribution. This indicates that altered axon-oligodendrocyte integrity exists after neonatal hyperoxia exposure and these changes may result in axon dysfunction.

\section{Functional deficits accompany abnormalities in myelin and axon ultrastructure}

These molecular analyses provide evidence that neonatal hyperoxia exposure disrupts the proper temporal and spatial interaction of the axon-oligodendrocyte complex, ultimately resulting in lasting axonopathy. These data, along with our previous findings that hyperoxia decreased fractional anisotropy in the adult subcortical WM (Schmitz et al., 2011; Schmitz et al., 2012), suggest lasting functional consequences after hyperoxia.

It is well established that disturbing normal myelination in the WM (i.e., hypomyelination, dysmyelination) alters the conduction velocity of the underlying axons, and models of demyelination have demonstrated these abnormal electrophysiological properties in the WM (Aguirre et al., 2007; Crawford et al., 2009). Axon caliber has been shown to influence action potential propagation and current amplitude directly (Waxman et al., 1995).

CAPs in the CC of the subcortical WM at both P30 and P60 revealed a similar pattern. The animals exposed to neonatal hyperoxia displayed a reduction in mean $\mathrm{M}$ and $\mathrm{UM}$ wave amplitude. A significant decrease in conduction velocity was also present in the $\mathrm{M}$ wave at $\mathrm{P} 30$ and $\mathrm{P} 60$. A change in conduction velocity was observed for the UM wave at P30, but not P60. These data support our previous in vivo studies and indicate that the cellular and ultrastructural changes after neonatal hyperoxia lead to long-term functional deficits in the conduction properties of the adult mouse WM. Interestingly, similar changes in conduction velocity and amplitude have been observed in the optic nerve of PLP knock-outs (Gutiérrez et al., 1995). These studies, along with our electrophysiological data, demonstrate the importance of proper axon-oligodendrocyte interaction mediated by PLP in the function of myelinated axons.

Recent studies have also examined the effect of neonatal hyperoxia exposure on motor coordination at P30 and P53 (Schmitz et al., 2012). Mice in the hyperoxia group displayed fine motor coordination deficits on a complex running wheel task (Schmitz et al., 2012). Interestingly, these mice also showed increased running activity (maximum velocity of meters run) on the conventional/training running wheel. Both characteristics are associated with reduced fractional anisotropy in the same subjects. This indicates that mice exposed to neonatal hyperoxia not only exhibit cellular, structural, and physiological abnormalities in the WM, but that motor coordination and activity of the mice are also affected. In addition, it suggests that hyperoxia-induced WM injury may have a role in attention deficit hyperactivity 
disorder and that the neonatal hyperoxia model may be a useful tool in the study of this disorder.

\section{References}

Aguirre A, Dupree JL, Mangin JM, Gallo V (2007) A functional role for EGFR signaling in myelination and remyelination. Nat Neurosci 10:9901002. CrossRef Medline

Allin MP, Kontis D, Walshe M, Wyatt J, Barker GJ, Kanann RA, McGuire P, Rifkin L, Murray RM, Nosarti C (2011) White matter and cognition in adults who were born preterm. PLoS One 6:e24525. CrossRef Medline

Allin M, Rooney M, Griffiths T, Cuddy M, Wyatt J, Rifkin L, Murray RJ (2006) Neurological abnormalities in young adults born preterm. Neurol Neurosurg Psychiatry 77:495-499. CrossRef Medline

Back SA (2006) Perinatal white matter injury: the changing spectrum of pathology and emerging insights into pathogenetic mechanisms. Ment Retard Dev Disabil Res Rev 12:129-140. CrossRef Medline

Back SA, Luo NL, Borenstein NS, Levine JM, Volpe JJ, Kinney HC (2001) Late oligodendrocyte progenitors coincide with the developmental window of vulnerability for human perinatal white matter injury. J Neurosci 21:1302-1312. Medline

Back SA, Riddle A, McClure MM (2007) Maturation-dependent vulnerability of perinatal white matteer in premature birth. Stroke 38:724-730. CrossRef Medline

Bakhti M, Snaidero N, Schneider D, Aggarwal S, Möbius W, Janshoff A, Eckhardt M, Nave KA, Simons M (2013) Loss of electrostatic cellsurface repulsion mediates myelin membrane adhesion and compaction in the central nervous system. Proc Natl Acad Sci U S A 110:3143-3148. CrossRef Medline

Bancalari E, Claure N (2012) Control of oxygenation during mechanical ventilation in the premature patient. Clin Perinatol 39:563-572. CrossRef Medline

Baumann N, Pham-Dinh D (2001) Biology of oligodendrocyte and myelin in the mammalian central nervous system. Physiol Rev 81:871-927. Medline

Bradl M, Lassmann H (2010) Oligodendrocytes: biology and pathology. Acta Neuropathol 119:37-53. CrossRef Medline

Campagnoni AT, Skoff RP (2001) The pathobiology of myelin mutants reveal novel biological functions of the MBP and PLP genes. Brain Pathol 11:74-91. Medline

Castillo A, Sola A, Baquero H, Neira F, Alvis R, Deulofeut R, Critz A (2008) Pulse oxygen saturation levels and arterial oxygen tension values in newborns receiving oxygen therapy in the neonatal intensive care unit: is $85 \%$ to $93 \%$ an acceptable range? Pediatrics 121:882-889. CrossRef Medline

Chew LJ, Shen W, Ming X, Senatorov VV Jr, Chen HL, Cheng Y, Hong E, Knoblach S, Gallo V (2011) SRY-box containing gene 17 regulates the $\mathrm{Wnt} / \beta$-catenin signaling pathway in oligodendrocyte progenitor cells. J Neurosci 31:13921-13935. CrossRef Medline

Craig A, Ling Luo N, Beardsley DJ, Wingate-Pearse N, Walker DW, Hohimer AR, Back SA (2003) Quantitative analysis of perinatal rodent oligodendrocyte lineage progression and its correlation with human. Exp Neurol 181:231-240. CrossRef Medline

Crawford DK, Mangiardi M, Xia X, López-Valdés HE, Tiwari-Woodruff SK (2009) Neuroscience 164:1407-1421.

Dashiell SM, Tanner SL, Pant HC, Quarles RH (2002) Myelin associated glycoprotein modulates expression and phosphorylation of neuronal cytoskeletal elements and their associated kinases. J Neurochem 81:12631272. CrossRef Medline

Davis JM, Auten RL (2010) Maturation of the antioxidant system and the effects on preterm birth. Semin Fetal Neonatal Med 15:191-195. CrossRef Medline

Deng W, Pleasure J, Pleasure D (2008) Progress in periventricular leukomalacia. Arch Neurol 65:1291-1295. CrossRef Medline

Felderhoff-Mueser U, Bittigau P, Sifringer M, Jarosz B, Korobowicz E, Mahler L, Piening T, Moysich A, Grune T, Thor F, Heumann R, Bührer C, Ikonomidou C (2004) Oxygen causes cell death in the developing brain. Neurobiol Dis 2004;17:273-282. CrossRef Medline

Ferguson LP, Durward A, Tibby SM (2012) Relationship between arterial partial oxygen pressure after resuscitation from cardiac arrest and mortality in children. Circulation 126:335-342. CrossRef Medline

Georgeson GD, Szony BJ, Streitman K, Varga IS, Kovács A, Kovács L, László A (2002) Antioxidant enzyme activities are decreased in preterm infants and in neonates born by caesarean section. Eur J Obstet Gynecol Reprod Biol 103:136-139. CrossRef Medline

Gerstner B, DeSilva TM, Genz K, Armstrong A, Brehmer F, Neve RL, Felderhoff-Mueser U, Volpe JJ, Rosenberg PA (2008) Hyperoxia causes maturation-dependent cell death in the developing white matter. J Neurosci 28:1236-1245. CrossRef Medline

Guerra-Wallace MM, Casey FL 3rd, Bell MJ, Fink EL, Hickey RW (2013) Hyperoxia and hypoxia in children resuscitated from cardiac arrest. Pediatr Crit Care Med 14:e143-8. CrossRef Medline

Gutiérrez R, Boison D, Heinemann U, Stoffel W (1995) Decompaction of CNS myelin leads to a reduction of the conduction velocity of action potentials in optic nerve. Neurosci Lett 195:93-96. CrossRef Medline

Horsburgh K, Reimer MM, Holland P, Chen G, Scullion G, Fowler JH (2011) Axon-glial disruption: the link between vascular disease and Alzheimer's disease? Biochem Soc Trans 39:881-885. CrossRef Medline

Iwata S, Nakamura T, Hizume E, Kihara H, Takashima S, Matsuishi T, Iwata O (2012) Qualitative Brain MRI at Term and Cognitive Outcomes at 9 Years After Very Preterm Birth. Pediatrics 129:e1138-47. CrossRef Medline

Jakovcevski I, Filipovic R, Mo Z, Rakic S, Zecevic N (2009) Oligodendrocyte development and the onset of myelination in the human fetal brain. Front Neuroanat 3:5. CrossRef Medline

Khwaja O, Volpe JJ (2008) Pathogenesis of cerebral white matter injury of prematurity. Arch Dis Child Fetal Neonatal Ed 93:153-161. CrossRef Medline

Kinney HC (2006) The near-term (late preterm) human brain and risk for periventricular leukomalacia: a review. Semin Perinatol 30:81-88. CrossRef Medline

Kirkpatrick LL and Brady ST (1999) Cytoskeleton of neurons and glia. In: Basic neurochemistry: molecular cellular and medical aspects (Siegel GJ, Agranoff BW, Albers RW, Fisher SK, Uhler MD, eds), pp 155-174. Philadelphia: Lippincott-Raven.

Lee JW, McElrath T, Chen M, Wallace DK, Allred EN, Leviton A, Dammann O (2013) Pregnancy disorders appear to modify the risk for retinopathy of prematurity associated with neonatal hyperoxia and bacteremia. J Matern Fetal Neonatal Med Feb 14.

Leviton A, Allred E, Kuban KC, Dammann O, O’Shea TM, Hirtz D, Schreiber MD, Paneth N (2010) Early Blood Gas Abnormalities and the Preterm Brain. Am J Epidemiol 172:907-916. CrossRef Medline

Litt J, Taylor HG, Klein N, Hack MJ (2005) Learning disabilities in children with very low birth weight: prevalence, neuropsychological correlates, and educational interventions. J Learn Disabil 38:130-141. CrossRef Medline

Liu Q, Xie F, Alvarado-Diaz A, Smith MA, Moreira PI, Zhu X, Perry G (2011) Neuro-filamentopathy in neurodegenerative diseases. Open Neurol J 5:58-62. CrossRef Medline

Marcus J, Dupree JL, Popko B (2002) Myelin-associated glycoprotein and myelin galactolipids stabilize developing axo-glial interactions. J Cell Biol 156:567-577. CrossRef Medline

Mathews TJ, Miniño AM, Osterman MJ, Strobino DM, Guyer B (2011) Annual summary of vital statistics. Pediatrics 127:146-157. CrossRef Medline

Ment LR, Vohr B, Allan W, Katz KH, Schneider KC, Westerveld M, Duncan CC, Makuch RW (2003) Change in cognitive function over time in very low -birth-weight infants. JAMA 289:705-711. CrossRef Medline

Nave KA (2010) Myelination and support of axonal integrity by glia. Nature 11;468:244-252. CrossRef Medline

Nave KA, Trapp BD (2008) Axon-glial signaling and the glial support of axon function. Annu Rev Neurosci 31:535-561. CrossRef Medline

Pan B, Fromholt SE, Hess EJ, Crawford TO, Griffin JW, Sheikh KA, Schnaar RL (2005) Myelin-associated glycoprotein and complementary axonal ligands, gangliosides, mediate axon stability in the CNS and PNS: neuropathology and behavioral deficits in single- and double-null mice. Exp Neurol 195:208-217. CrossRef Medline

Perrot R, Lonchampt P, Peterson AC, Eyer J (2007) Axonal neurofilaments control multiple fiber properties but do not influence structure or spacing of nodes of Ranvier. J Neurosci 27:9573-9584. CrossRef Medline

Perrot R, Berges R, Bocquet A, Eyer J (2008) Review of the multiple aspects of neurofilament functions and their possible contribution to neurodegeneration. Mol Neurobiol 38:27-65. CrossRef Medline

Piaton G, Gould RM, Lubetzki C (2010) Axon-oliodendrocyte interactions 
during developmental myelination, demyelination and repair. J Neurochem 114:1243-1260. CrossRef Medline

Poliak S, Peles E (2003) The Local Differentiation of Myelinated Axons at Nodes of Ranvier. Nat Rev Neurosci 4:968-980. CrossRef Medline

Quarles RH, Macklin WB, Morell P (2006) Myelin formation, structure and biochemistry. In: Basic neurochemistry, Ed 7 (Siegel GJ, Albers RW, Price D), pp 51-77. Amsterdam: Elsevier.

Ramani M, van Groen T, Kadish I, Bulger A, Ambalavanan N (2013) Neurodevelopmental impairment following neonatal hyperoxia in the mouse. Neurobiol Dis 50:69-75. CrossRef Medline

Reimer MM, McQueen J, Searcy L, Scullion G, Zonta B, Desmazieres A, Holland PR, Smith J, Gliddon C, Wood ER, Herzyk P, Brophy PJ, McCulloch J, Horsburgh K (2011) Rapid disruption of axon-glial integrity in response to mild cerebral hypoperfusion. J Neurosci 31:18185-18194. CrossRef Medline

Rios JC, Rubin M, St Martin M, Downey RT, Einheber S, Rosenbluth J, Levinson SR, Bhat M, Salzer JL (2003) Paranodal interactions regulate expression of sodium channel subtypes and provide a diffusion barrier for the node of Ranvier. J Neurosci 6;23:7001-7011.

Sánchez I, Hassinger L, Sihag RK, Cleveland DW, Mohan P, Nixon RA (2000) Local control of neurofilament accumulation during radial growth of myelinating axons in vivo. Selective role of site-specific phosphorylation. J Cell Biol 151:1013-1024. CrossRef Medline

Scafidi J, Fagel DM, Ment LR, Vaccarino FM (2009) Modeling premature brain injury and recovery. Int J Dev Neurosci 27:863-871. CrossRef Medline

Schmitz T, Ritter J, Mueller S, Felderhoff-Mueser U, Chew LJ, Gallo V (2011) Cellular changes underlying hyperoxia-induced delay of white matter development. J Neurosci 31:4327-4344. CrossRef Medline

Schmitz T, Endesfelder S, Reinert MC, Klinker F, Müller S, Bührer C, Liebetanz D (2012) Adolescent hyperactivity and impaired coordination after neonatal hyperoxia. Exp Neurol 235:374-379. CrossRef Medline

Schnaar RL, Lopez PH (2009) Myelin-associated glycoprotein and its axonal receptors. J Neurosci Res 87:3267-3276. CrossRef Medline

Simons M, Trajkovic K (2006) Neuro-glia communication in the control of oligodendrocyte function and myelin biogenesis. J Cell Sci 119: 4381-4389. CrossRef Medline

Skiöld B, Vollmer B, Böhm B, Hallberg B, Horsch S, Mosskin M, Lagercrantz H, Ådén U, Blennow M (2012) Neonatal magnetic resonance imaging and outcome at age 30 months in extremely preterm infants. J Pediatr 160:559-566. CrossRef Medline

Sorensen LC, Greisen G (2009) The brains of preterm newborns in clinically stable condition may be hyperoxygenated. Pediatrics 124:e958-e963. CrossRef Medline

Tanaka H, Ma J, Tanaka KF, Takao K, Komada M, Tanda K, Suzuki A, Ishibashi T, BabaH, Isa T, Shigemoto R, Ono K, Miyakawa T, Ikenaka K (2009) Mice with altered myelin proteolipid protein gene expression display cognitive deficits accompanied by abnormal neuron-glia interactions and decreased conduction velocities J Neurosci 29:83638371. CrossRef

Thompson DK, Inder TE, Faggian N, Johnston L, Warfield SK, Anderson PJ, Doyle LW, Egan GF (2011) Characterization of the corpus callosum in very preterm and fullterm infants utilizing MRI. Neuroimage 55:479-490. CrossRef Medline

Vital C, Vital A, Bouillot S, Favereaux A, Lagueny A, Ferrer X, Brechenmacher C, Petry KG (2003) Uncompacted myelin lamellae in peripheral nerve biopsy. Ultrastruct Pathol 27:1-5. Medline

Volpe JJ (2008) Hypoxic ischemic encephalopathy: periventricular leucomalacia. In: Neurology of the newborn, Ed 5 (Volpe JJ, ed), pp 360-379. Philadelphia: Elsevier.

Volpe JJ (2009) Brain injury in premature infants: a complex amalgam of destructive and developmental disturbances. Lancet Neurol 8:110-124. CrossRef Medline

Waxman SG, Kocsis JD, Stys PK (1995) The Axon: Structure, Function and Pathophysiology.

Weber T, Secher NJ (1979) Continuous measurement of transcutaneous fetal oxygen tension during labour. Br J Obstet Gynaecol 86:954-958. CrossRef Medline

Yin X, Crawford TO, Griffin JW, Tu Ph, Lee VM, Li C, Roder J, Trapp BD (1998) Myelin-associated glycoprotein is a myelin signal that modulates the caliber of myelinated axons. J Neurosci 18:1953-1962. Medline 